\title{
A 24-48 h fed Amblyomma americanum tick saliva immuno-proteome
}

\author{
Željko M Radulović ${ }^{1}$, Tae K Kim¹ ${ }^{1}$ Lindsay M Porter ${ }^{1}$, Sing-Hoi Sze ${ }^{2,3}$, Lauren Lewis ${ }^{1}$ and Albert Mulenga ${ }^{1 *}$
}

\begin{abstract}
Background: Multiple tick saliva proteins, the majority of which are unknown, confer tick resistance in repeatedly infested animals. The objective of this study was to identify the 24-48 $\mathrm{h}$ fed Amblyomma americanum tick saliva immuno-proteome. The 24-48 $\mathrm{h}$ tick-feeding phase is critical to tick parasitism as it precedes important events in tick biology, blood meal feeding and disease agent transmission. Fed male, 24 and $96 \mathrm{~h}$ fed female phage display cDNA expression libraries were biopanned using rabbit antibodies to 24 and $48 \mathrm{~h}$ fed $\mathrm{A}$. americanum female tick saliva proteins. Biopanned immuno-cDNA libraries were subjected to next generation sequencing, de novo assembly, and bioinformatic analysis.

Results: More than 800 transcripts that code for $24-48 \mathrm{~h}$ fed $A$. americanum immuno-proteins are described. Of the 895 immuno-proteins, 52\% (464/895) were provisionally identified based on matches in GenBank. Of these, 19\% (86/464) show high level of identity to other tick hypothetical proteins, and the rest include putative proteases (serine, cysteine, leukotriene A-4 hydrolase, carboxypeptidases, and metalloproteases), protease inhibitors (serine and cysteine protease inhibitors, tick carboxypeptidase inhibitor), and transporters and/or ligand binding proteins (histamine binding/lipocalin, fatty acid binding, calreticulin, hemelipoprotein, lgG binding protein, ferritin, insulin-like growth factor binding proteins, and evasin). Others include enzymes (glutathione transferase, cytochrome oxidase, protein disulfide isomerase), ribosomal proteins, and those of miscellaneous functions (histamine release factor, selenoproteins, tetraspanin, defensin, heat shock proteins).

Conclusions: Data here demonstrate that A. americanum secretes a complex cocktail of immunogenic tick saliva proteins during the first 24-48 h of feeding. Of significance, previously validated immunogenic tick saliva proteins including AV422 protein, calreticulin, histamine release factor, histamine binding/lipocalins, selenoproteins, and paramyosin were identified in this screen, supporting the specificity of the approach in this study. While descriptive, this study opens opportunities for in-depth tick feeding physiology studies.
\end{abstract}

Keywords: Amblyomma americanum, Tick saliva proteins, Biopanning, Immuno-proteome

\section{Background}

Ticks are reservoirs and vectors of numerous animal and human pathogenic microorganisms, including bacteria, viruses, and protozoans. Although in terms of public health impact ticks are considered second to mosquitoes, they surpass any arthropod vector in terms of diversity of disease agents that they transmit and their impact on livestock production [1,2]. For many years ticks and tick borne diseases were considered a veterinary problem, where economic losses run into several millions of US\$

\footnotetext{
* Correspondence: a-mulenga@tamu.edu

'Department of Entomology, AgriLife Research, Texas A \& M University, 2475 TAMU, College Station TX77843, USA

Full list of author information is available at the end of the article
}

annually [3]. In Brazil alone, loses due to the cattle tick, Rhipicephalus microplus were estimated at 2 billion US\$ annually [4]. However in recent years, the impact of human tick borne diseases in public health have been growing.

Amblyomma americanum, previously considered a nuisance, is among important tick species in public health [5]. This tick previously established in southeastern United States has now spread to the northeast $[6,7]$. $A$. americanum has been reported as the most predominant tick species found on humans in this part of the United States [8]. This species transmits several human tick borne disease agents including Ehrlichia chaffeensis, Ehrlichia ewingii, and Francisella tularensis 
[9-14]. A. americanum also transmits the causative agents of southern tick associated rash illness (STARI) [15,16], Ehrlichia ruminatium-like Panola Mountain Ehrlichia (PME) [17,18], and has also been linked to Heartland virus [19]. There is also evidence that $A$. americanum may transmit Rickettsia amblyommii to humans [20]. In veterinary health, A. americanum transmits Theileria cervi to deer [21], and E. ewingii to dogs [22]. There are reports of mortality in deer fawns that were attributed to a combination of heavy $A$. americanum infestation and T. cervi infections [23].

Although chemical acaricide based strategies represent the dominant prevention method against tick borne disease infections, the focus is moving to developing new, more efficient and environmentally friendly strategies [24]. One of the possible alternative strategies could be the production of anti-tick vaccines. This idea is not new, as it is known for more than 80 years that immunity to tick infestation could be induced by vaccination with a whole tick or salivary gland homogenates $[25,26]$. Currently, the focus is on identification of efficacious tick protein antigens, which could be expressed as recombinant vaccine antigens [27-29]. Generally, there are two groups of these antigens. The first, so called "exposed antigens" includes tick proteins that are injected into the host during the tick feeding process. The second group of antigens, known as "concealed antigens", refers to molecules which are not in direct contact with the host and usually do not induce an immunological response, such as tick gut components [30]. In our lab we are interested in "exposed antigens" and in the prospect of finding target anti-tick vaccine antigens, in which subsequent tick infestations of immunized animals will trigger an anamnestic (elevated) antibody response and serve as a "de facto" booster shot. In this way the need for manual administering of booster shots to the host will be eliminated.

Bioactive molecules in tick saliva play important roles in facilitating blood meal feeding and transmission of tick borne disease agents. The tick feeding style of lacerating host tissue and then sucking up blood that bleeds into the wounded area is expected to stimulate host defense responses aimed at stopping blood loss and initiating tissue repair responses. Expected host responses to tick feeding activity include vasoconstriction, platelet aggregation, fibrin clot formation, inflammation, and complement activation [31]. Studies to find tick saliva proteins that facilitate feeding were modeled after the expected host responses to tick feeding. In this way vasodilators [32-35], inhibitors of platelet aggregation [36-38], anti-coagulants [39-52], anti-inflammatory proteins [53,54], and inhibitors of complement activation [55-59] were described in several tick species. Other studies have identified apparent pain blockers, a metallo dipeptidyl carboxypeptidase from saliva of Ixodes scapularis [60] and a thiol-activated metalloendopeptidase from saliva of $R$. microplus [61]. In a related study, Mulenga et al. [62] and Mulenga and Azad [63] described a functional histamine release factor (HRF) in tick saliva. The presence of HRF in tick saliva was considered counter-intuitive in that HRF is pro-inflammatory [64], and on the other hand, ticks should stop the inflammation response to feed successfully.

The idea of immunizing animals against tick feeding was prompted by observations that repeated tick infestation of animals conferred protective anti-tick immunity $[65,66]$. In subsequent studies immune sera of tick resistant animals bound numerous protein bands from tick salivary gland protein extracts $[67,68]$, suggesting that numerous tick saliva proteins provoked anti-tick immunity in repeatedly infested animals. The objective of this study was to identify and characterize $24-48 \mathrm{~h}$ fed A. americanum tick saliva immunogenic protein coding cDNAs. We are interested in 24-48 h post attachment tick saliva proteins because this tick feeding stage precedes some of the most important facets of tick parasitism, blood meal feeding, transmission, and acquisition of tick borne disease agents.

\section{Methods}

\section{Ticks}

Unfed $A$. americanum ticks for this study were purchased from tick laboratories located at Texas A\&M University and Oklahoma State University. In our lab, ticks were kept at favorable conditions (room temperature and $>85 \%$ relative humidity) and fed on New Zealand White Rabbits according to the animal use protocol \#2011-189 approved by Texas A \& M University IACUC to AM. Six male ticks were pre-fed for three days before placing female ticks to feed. To prevent ticks from entering the inner ear, they were restricted onto the top of the rabbit ear using an orthopedic stockinet containment cell adhered onto rabbit skin using the Kamar Adhesive (Kamar Products Inc., Zionsville, IN). Fed male ticks were collected from several feeding experiments, while female ticks were manually detached at 24 and $96 \mathrm{~h}$ post attachment and processed for RNA extraction as described below.

Following detachment, pieces of rabbit skin were manually cleaned off the tick mouthparts using soft tissue forceps. Subsequently ticks were washed in dietylpyrocarbonate (DEPC) treated water and dried on a paper towel. Pools of eight to ten ticks were chopped up using a sharp razor blade and homogenized in $1 \mathrm{~mL}$ TRIzol (Life Technologies, Carlsbad, CA, USA) and stored at $-80^{\circ} \mathrm{C}$ until total RNA extraction.

\section{Messenger RNA extraction and CDNA preparation}

Total RNA was extracted according to the detailed protocol provided by TRIzol reagent manufacturer (Life 
Technologies). Isolation of mRNA from prepared total RNA was done using Straight A's ${ }^{\mathrm{TM}}$ mRNA Isolation System (Novagen, Madison, WI, USA). Total RNA was mixed with Magnetictight Oligo(dT) Particles $(20 \mu \mathrm{g}$ of particles per $1 \mu \mathrm{g}$ of total RNA). After appropriate washes mRNA was eluted in $0.5 \mathrm{~mL}$ of nuclease free water by incubating at $60^{\circ} \mathrm{C}$ for 10 minutes. Subsequently mRNA was concentrated by mixing sample with $2 \mu \mathrm{L}$ of Glycogen $(10 \mathrm{mg} / \mathrm{mL}), 50 \mu \mathrm{L}$ of $3 \mathrm{M}$ sodium acetate, and $331 \mu \mathrm{L}$ of 2-propanol, and centrifugation at $14000 \times \mathrm{g}$ for $5 \mathrm{mi}$ nutes. The mRNA pellet was washed with $0.5 \mathrm{~mL}$ of $70 \%$ ethanol and dissolved in $25 \mu \mathrm{L}$ of nuclease free water. Concentration of mRNA samples was determined by measuring absorbance at $260 \mathrm{~nm}$ using the DU 640B spectrophotometer (Beckman Coulter, Brea, CA, USA).

\section{Fed male, 24 and $96 \mathrm{~h}$ fed female $A$. americanum phage display expression cDNA libraries}

Phage display cDNA expression libraries were constructed using T7Select OrientExpress cDNA cloning System (Novagen, Madison, WI, USA). A total of $4 \mu \mathrm{g}$ of mRNA was used to synthesize cDNA using the OrientExpress $^{\mathrm{TM}}$ Oligo(dT) cDNA Synthesis Kit (Novagen, Madison, WI, USA) according to instructions. Prior to proceeding with the rest of the protocol, success of cDNA synthesis was verified by PCR amplification of tick actin gene sequence using ${ }^{5^{\prime}}$ GGACAGCTACGTGG GCGACGAGG $^{3}$ and ${ }^{5}$ CGATTTCACGCTCAGCCGT GGTGG $^{3}$ primers, and MyTaq Red Mix (Bioline USA Inc., Taunton, MA, USA). Prepared cDNA was stored at $-20^{\circ} \mathrm{C}$. Following verification of cDNA synthesis, cDNA ends were modified by ligating EcoRI and HindIII sticky ends at the $5^{\prime}$ and 3 ' ends. Subsequently modified cDNA was ligated to directional EcoRI/HindIII linkers. After appropriate treatment and fractionation to remove excess linkers, cDNA was ligated into T7Select vector arms using T4 ligase (Novagen, Madison, WI, USA). Following ligation the library was packaged using T7 packaging extracts previously thawed on ice and mixed by stirring with a pipet tip. The packaging reaction was incubated for $2 \mathrm{~h}$ at room temperature and was stopped by adding $270 \mu \mathrm{L}$ of sterile M9TB medium with carbenicillin (final concentration $50 \mu \mathrm{g} / \mathrm{mL}$ ). The packaging reaction was mixed by inverting with $20 \mu \mathrm{L}$ of chloroform and stored at $4^{\circ} \mathrm{C}$.

The phage titer in the packaging reaction was determined by plaque assay [69]. Serial dilutions of packaging reaction in M9TB medium with carbenicillin, ranging from $1: 10^{3}$ to $1: 10^{6}$, were prepared. Fresh culture of Escherichia coli BLT5403 strain $\left(\mathrm{OD}_{600}=1\right)$ in M9TB medium with carbenicillin was used as host cells for T7 phages. From each dilution, $100 \mu \mathrm{L}$ were mixed with $250 \mu \mathrm{L}$ of host cells and $3 \mathrm{~mL}$ of molten top agarose, and plated on LB agar plates with carbenicillin (final concentration $50 \mu \mathrm{g} / \mathrm{mL})$. Plates were incubated at $37^{\circ} \mathrm{C}$ for $4 \mathrm{~h}$ and formed plaques were counted. The phage titer was calculated according to the formula provided in the user manual. After determining the titer, the library was amplified using the plate lysate amplification protocol according to instructions in the user manual. Phage was diluted to $1 \times 10^{6}$ per $10 \mathrm{~mL}$ of host cells $\left(\mathrm{OD}_{600}=\right.$ 0.6-1.0). One $\mathrm{mL}$ of phages/host cells mixture was combined with $10 \mathrm{~mL}$ of molten top agarose and plated on $150 \mathrm{~mm}$ LB agar plates with carbenicillin. Plates were incubated at $37^{\circ} \mathrm{C}$ for $3-4$ hours. When plaques on the plates became nearly confluent, each plate was incubated with $10 \mathrm{~mL}$ of phage extraction buffer $(20 \mathrm{mM}$ Tris$\mathrm{HCl} \mathrm{pH} \mathrm{8.0,} 100 \mathrm{mM} \mathrm{NaCl}, 6 \mathrm{mM} \mathrm{MgSO}_{4}$ ) overnight at $4^{\circ} \mathrm{C}$. Phage elutes were collected, mixed with $0.5 \mathrm{~mL}$ of chloroform, and clarified by centrifugation at $3000 \mathrm{~g}$ for 5 minutes. The supernatant was mixed with 0.1 volume of sterile $80 \%$ glycerol and stored at $-80^{\circ} \mathrm{C}$. The titer of amplified libraries was determined using protocol described above.

\section{Verifying quality of phage display libraries}

Following amplification, the quality of the amplified libraries was verified by checking the length of cloned cDNA sequences. 10-15 plaques per library were inoculated in $5 \mathrm{~mL}$ of host cells (fresh culture of BLT5403 strain in LB medium with cabenicillin, $\left.\mathrm{OD}_{600}=0.5-0.6\right)$. Culture was incubated at $37^{\circ} \mathrm{C}$ with shaking until lysis was observed. Lysate was clarified by centrifugation at $8000 \mathrm{~g}$ for 10 minutes. For phage extraction $1.25 \mathrm{~mL}$ of 20\% PEG-8000/2.5 M NaCl were mixed with $5 \mathrm{~mL}$ of the lysate and incubated on ice at least 30 minutes. Phages were pelleted by centrifugation at $11000 \mathrm{~g}$ for 20 minutes, and then re-suspended in $100 \mu \mathrm{L}$ of STE Buffer (10 mM Tris- $\mathrm{HCl} \mathrm{pH}$ 8.0, $100 \mathrm{mM} \mathrm{NaCl}, 1 \mathrm{mM}$ EDTA). The suspension was centrifuged at $14000 \mathrm{~g}$ for 10 minutes and the supernatant containing phages was transferred to a fresh tube. Phage extracts were used as templates for PCR amplification of cloned cDNA using the T7Select UP ( ${ }^{5}$ GGAGCTGTCGTATTCCAGTC ${ }^{3}$ ') and T7Select DOWN ( ${ }^{5}$ AACCCCTCAAGACCCGTT $\left.\mathrm{TA}^{3}\right)$ primers. PCR products were separated by electrophoresis on $2 \%$ agarose gel.

\section{Production of antibodies to fed male and $24 \mathrm{~h}$ female $A$. americanum tick saliva proteins}

Production of antibodies to $48 \mathrm{~h}$ fed $A$. americanum tick saliva proteins was previously described [70]. The same protocol was used to produce antibodies to $24 \mathrm{~h}$ fed $A$. americanum tick saliva proteins. Rabbits were infested with 30 female ticks (15 per ear) every $24 \mathrm{~h}$ three times per week. This routine was repeated for four times after which antibody response to tick saliva proteins was verified. Blood was collected from rabbits approximately 
two weeks after the last round of tick feeding according to the protocol \#2011-189 approved by Texas A \& M University IACUC to AM. Rabbits were exsanguinated following humane standards by qualified veterinarians as approved by the Texas A \& M University Comparative Medicine Program. Blood was left to clot overnight at $4^{\circ} \mathrm{C}$ to achieve maximum serum separation. Collected serum was stored at $-80^{\circ} \mathrm{C}$. Prior to tick infestations, rabbits were bled according to approved Texas A \& M University protocols to collect pre-immune serum controls.

\section{Biopanning protocol and phage extraction}

Four rounds of biopanning were done to generate immuno-reactive biopanned libraries. In the first step, parent libraries, fed male, 24 and $96 \mathrm{~h}$ fed female phage display libraries were immuno-screened with antibodies to 24 and $48 \mathrm{~h}$ fed $A$. americanum tick saliva proteins using a biopanning kit according to instructions by the manufacturer (Novagen, Madison, WI, USA). 96-well EIA/RIA plates (Corning, Corning, NY, USA) were used in our biopanning protocol. Prior to antibody application, wells were rinsed with deionized water several times. In the first step, a $100 \mu \mathrm{L}$ of serum diluted 1:4 or 1:10 in ELISA Coating Buffer (BioLegend, San Diego, CA, USA) were applied per well and left overnight at $4^{\circ} \mathrm{C}$. After antibody binding, wells were washed three times with ELISA coating buffer. Subsequently wells were incubated at $4^{\circ} \mathrm{C}$ overnight with $200 \mu \mathrm{L}$ of $5 \%$ solution of blocking reagent provided with the kit. Following blocking, wells were washed 5 times with deionized water. Following washing wells were incubated with $1 \times 10^{8}$ pfu (plaque forming units) of each parent library in $100 \mu \mathrm{L}$ of TBST (Tris-Buffered Saline with $0.05 \%$ Tween) overnight at $4^{\circ} \mathrm{C}$. Subsequently unbound phages were removed by washing $(5 \times)$ with TBST. To elute bound phages, wells were incubated with $200 \mu \mathrm{L}$ of T7 phage elution buffer ( $0.1 \%$ SDS solution) at room temperature for $20 \mathrm{~min}$. Eluted phages were amplified by inoculating $50 \mathrm{~mL}$ of host cells (fresh culture of BLT5403 strain in LB medium with cabenicillin, $\mathrm{OD}_{600}=0.5-0.6$ ) and incubation at $37^{\circ} \mathrm{C}$ with shaking until lysis of host cells was observed. The lysate was clarified by centrifugation at $8000 \mathrm{~g}$ for 10 minutes. The clarified extract was subjected to phage extraction using $12.5 \mathrm{~mL}$ of $20 \%$ PEG8000/2.5 M sodium chloride. Pelleted phages were resuspended in $1 \mathrm{~mL}$ of STE buffer. Titer of purified phages was determined as derscribed above. The biopanning protocol was repeated four times to generate immunoreactive biopanned libraries. To generate false positive controls, parent libraries were also biopanned with rabbit pre-immune serum as described above.

\section{Next generation sequencing}

Parent libraries (fed male, 24 and $96 \mathrm{~h}$ fed female libraries) and biopanned libraries were subjected to next generation sequencing using Illumina HiSeq2000 system with the following options: paired-end sequencing, read length of $100 \mathrm{bp}$, and 800,000 reads per sample. Libraries were prepared for sequencing by PCR amplification using AccuPrime Pfx DNA Polymerase (Invitrogen - Life Technologies, Carlsbad, CA, USA). $100 \mu \mathrm{L}$ PCR reaction contained $2 \mu \mathrm{L}$ of phages, $10 \mu \mathrm{L}$ of $10 \times$ AccuPrime Pfx Reaction Mix, $3 \mu \mathrm{L}$ of each T7Select UP and T7Select DOWN primer $(10 \mu \mathrm{M}), 1 \mu \mathrm{L}$ of AccuPrime $P f x$ DNA Polymerase $(2.5$ units/ $\mu \mathrm{L})$, and $81 \mu \mathrm{L}$ of nuclease free water. PCR cycling conditions were initial denaturation of $2 \mathrm{~min}$ at $95^{\circ} \mathrm{C}$, followed by 35 cycles for $15 \mathrm{~s}$ at $95^{\circ} \mathrm{C}, 30 \mathrm{~s}$ at $50^{\circ} \mathrm{C}$, and $3 \mathrm{~min}$ at $68^{\circ} \mathrm{C}$. Following amplification, PCR products were purified using MicroElute Cycle-Pure Kit (Omega Bio-Tek, Norcross, GA, USA). Elution was performed in $20 \mu \mathrm{L}$ of Elution Buffer and samples were stored at $-20^{\circ} \mathrm{C}$ until sequencing started.

\section{De novo assembly and sequence analysis}

Sequence reads trimmed at the default .05 limit value were de novo assembled using CLC Genomics Workbench software version 6.0.2 (CLC Bio-Qiagen, Cambridge, MA, USA), with all other parameters set to the default settings. Contigs that were found in pre-immune serum biopanned libraries were considered non-specific and eliminated from further analysis. To annotate assembled contigs, sequences were batch scanned against tick sequences in GenBank using BlastX homology search. The Blast search reported in this study was done during March 2014, and there is a possibility that findings may change when new sequences are deposited in GenBank. To identify contigs that were present in multiple biopanned libraries, contig lists were compared using the bl2seq pairwise alignment tool at NCBI. Multiple sequence alignments were done using MacVector version 12 (Mac Vector, Inc., Cary, NC, USA).

\section{Results and discussion}

Biopanning, next generation sequencing and de novo assembly

Three parent phage display cDNA expression libraries, 24 h (PL1) and $96 \mathrm{~h}$ (PL2) fed female and fed male (PL3) $A$. americanum ticks, were successfully immunoscreened with antibodies (Ab) to 24 and $48 \mathrm{~h}$ fed female tick saliva proteins to generate four biopanned libraries (BPs). The 4 BPs include PL1 biopanned with $24 \mathrm{~h} \mathrm{Ab}$ (BP6) and $48 \mathrm{~h} \mathrm{Ab}$ (BP10), PL2 biopanned with $48 \mathrm{~h} \mathrm{Ab}$ (BP13-14), and PL3 biopanned with $48 \mathrm{~h} \mathrm{Ab}$ (BP15-16) (Table 1). Biopanning PL1-3 with pre-immune control serum obtained from rabbits prior to tick infestation generated negative control BPs (N-BP1-3) (not shown). PCR amplified PLs, BPs, and N-BPs were successfully sequenced using Illumina HiSeq2000 and individually de novo assembled using CLC Genomics Workbench. As 
Table 1 Sequence reads and contig numbers in parent (PL) and biopanned (BP) libraries

\begin{tabular}{llll}
\hline Library name & Description & Number of sequence reads & $\begin{array}{c}\text { Number of de novo } \\
\text { assembled contigs }\end{array}$ \\
\hline PL1 & 24 $\mathrm{h}$ fed female tick & 5889 \\
PL2 & $96 \mathrm{~h}$ fed female tick & 1.400 .000 & 6240 \\
PL3 & Fed male tick & 1.000 .000 & 5464 \\
BP6 & PL1 biopanned with antibodies to 24 h A. americanum TSP ${ }^{1}$ & 3.700 .000 & 109 \\
BP10 & PL1 biopanned with antibodies to 48 h A. americanum TSP ${ }^{1}$ & 1.700 .000 & 117 \\
BP13-14 & PL2 biopanned with antibodies to 48 h A. americanum TSP ${ }^{1}$ & 4.000 .000 & 419 \\
BP15-16 & PL3 biopanned with antibodies to 48 h A. americanum TSP ${ }^{1}$ & 4.200 .000 & 266 \\
\hline
\end{tabular}

${ }^{1}$ Tick saliva proteins.

summarized in Table 1, biopanning of PL1 (5889 contigs) with $\mathrm{Ab}$ to 24 and $48 \mathrm{~h} A$. americanum tick saliva proteins yielded 109 (BP6) and 117 (BP10) contigs, respectively. Likewise biopanning of PL2 (6240 contigs) and PL3 (5464 contigs) with antibodies to $48 \mathrm{~h} \mathrm{~A}$. americanum tick saliva proteins yielded 419 (BP13-14) and 266 (BP15-16) contigs, respectively. BlastX analysis showed that all contigs in N-BPs and 16 contigs in biopanned libraries coded for phage proteins. This analysis identified 895 contigs that code putative immunogenic A. americanum tick saliva proteins secreted during the first 24-48 h of feeding. The strategy to immuno-screen with antibodies to $24 \mathrm{~h}$ A americanum tick saliva proteins was to attempt finding proteins that are injected into the host within $24 \mathrm{~h}$ of tick feeding. Additionally immuno-screening male tick phage library identified immunogenic proteins that are shared between female and male ticks. Data in Table 2 show that 56\% (60/109) of BP6 contigs were not found in other biopanned libraries, while $20 \%(52 / 266)$ of BP15-16 contigs were also found in female tick biopanned libraries.

Of the 895 contigs from the A. americanum immunotranscriptome, 431 (listed in an Additional file 1) did not show amino acid identities to previously annotated proteins in GenBank, while the remaining 464 sequences were provisionally annotated on the basis of their identity to protein sequences in GenBank. The provisionally annotated sequences include cross-tick species conserved orphan tick saliva proteins (Table 2), proteases (Table 3), protease inhibitors (Table 4), transporters and/ or binding proteins (Table 5), enzymes (Table 6), ribosomal proteins (Table 7), and proteins of miscellaneous functions (Table 8). For clarity, the rest of this discussion is arranged under the different classes of provisionally identified proteins in this study.

\section{Orphan immunogenic tick saliva protein coding cDNAs}

Table 2 lists 86 contig sequences that code for orphan immunogenic $A$. americanum tick saliva proteins that show high amino acid identity with other tick proteins, but not with non-tick organisms. Of the 86 sequences,
12 sequences each were identified in BP6 and BP10, while 34 and 28 sequences were identified in BP13-14 and BP15-16, respectively. It is notable that except for 23 sequences that show similarity exclusively to other metastriata tick proteins, the remaining 63 sequences show similarity either exclusively to Ixodes spp. ticks or to both metastriata and prostriata tick proteins. In general metastriata and prostriata tick protein sequences tend to show low amino acid conservation. Thus, the 63 sequences in Table 2 that show high conservation could represent important immunogenic tick saliva proteins that regulate key tick physiological functions. Observations here that majority of $A$. americanum sequences in Table 2 show similarity to prostriata than metastriata tick proteins could be due to that at the time of this write up, there were more I. scapularis protein sequence entries in GenBank than metastriata tick entries. Thus some of the sequences that show similarity exclusively to I. scapularis might also be conserved in other metastriata ticks if genome sequence data became available.

Some notable observations in Table 2 include the GBAI01000007 sequence, which showed 74-97\% amino acid identity with putative immunogenic secreted proteins from saliva of Rhipicephalus annulatus, Haemaphysalis quinghaiensis, Haemaphysalis longicornis, and I. scapularis (not shown). Likewise sequence GBAI01000013 showed similarity to mucin-like proteins previously described in Dermacentor variabilis and Amblyomma variegatum [71,72]. Mucins are heavily glycosylated proteins with numerous functions including lubrication, cell signaling, and host defense against pathogens [73,74]. Sequences GBAI01000021, GBAK01000213, and GBAL01000042 match with recently described $A$. americanum secreted saliva protein AV422 [70]. This cross-tick species conserved protein is characterized with 14 conserved cysteine amino acid residues predicted to form 7 disulfide bonds. Mulenga et al. [70] revealed the role of described protein in interrupting host hemostasis and complement activation. It is also interesting to note that a protein that is $97 \%$ identical to AV422 was recently described in the $R$. microplus proteome [75]. Additionally, $R$. microplus proteome 
Table 2 Amblyomma americanum tick saliva proteins encoding cDNAs conserved in other tick species, but not in mammals

\begin{tabular}{|c|c|c|c|}
\hline Accession\# & Source library & Top matches in GenBank [accession\#] & e-values \\
\hline \multirow[t]{4}{*}{ GBAI01000007 } & BP6 & unknown larval protein mRNA, complete cds Rhipicephalus annulatus [EF675686.1] & $1^{\mathrm{e}-124}$ \\
\hline & & immunogenic protein mRNA, complete cds Haemaphysalis longicornis [GQ499841.1] & $5^{e^{-111}}$ \\
\hline & & secreted protein, putative, mRNA Ixodes scapularis [XP_002399589.1] & $6^{e^{-77}}$ \\
\hline & & Hq05 mRNA, complete cds Haemaphysalis qinghaiensis [AY626791.1] & $4^{e-70}$ \\
\hline \multirow[t]{2}{*}{ GBAJ01000081 } & $\mathrm{BP} 10$ & unknown larval protein mRNA, complete cds Rhipicephalus annulatus [EF675686.1] & $1^{\mathrm{e}-06}$ \\
\hline & & immunogenic protein mRNA, complete cds Haemaphysalis longicornis [GQ499841.1] & 0.003 \\
\hline \multirow[t]{2}{*}{ GBAJ01000082 } & BP10 & unknown larval protein mRNA, complete cds Rhipicephalus annulatus [EF675686.1] & $2^{e^{-09}}$ \\
\hline & & immunogenic protein mRNA, complete cds Haemaphysalis longicornis [GQ499841.1] & $7^{\mathrm{e}-07}$ \\
\hline \multirow[t]{3}{*}{ GBAI01000013 } & BP6 & mucin-like protein Dermacentor variabilis [ACF35532.1] & $4^{\mathrm{e}-40}$ \\
\hline & & salivary mucin Amblyomma variegatum [DAA34695.1] & $2^{\mathrm{e}-24}$ \\
\hline & & chitinase, putative Ixodes scapularis [XP_002404149.1] & $6^{\mathrm{e}-22}$ \\
\hline \multirow[t]{3}{*}{ GBAK01000244 } & BP13-14 & mucin-like protein Dermacentor variabilis [ACF35532.1] & $3^{\mathrm{e}-41}$ \\
\hline & & salivary mucin Amblyomma variegatum [DAA34695.1] & $5^{\mathrm{e}-24}$ \\
\hline & & chitinase, putative Ixodes scapularis [XP_002404149.1] & $4^{\mathrm{e}-23}$ \\
\hline GBAK01000411 & BP13-14 & Cht mRNA for chitinase, complete cds Haemaphysalis longicornis [AB074977.1] & $7^{e^{-12}}$ \\
\hline GBAI01000021 & BP6 & AV422 mRNA, complete cds Amblyomma americanum [KC222016.1] & $2^{\mathrm{e}-08}$ \\
\hline GBAK01000213 & BP13-14 & & 6 \\
\hline GBAL01000042 & BP15-16 & & $7^{\mathrm{e}-35}$ \\
\hline GBAI01000030 & BP6 & hypothetical secreted protein 1447 mRNA, complete cds Amblyomma variegatum [BK007660.1] & $4^{\mathrm{e}-09}$ \\
\hline GBAI01000032 & BP6 & unknown Haemaphysalis qinghaiensis [ABQ96857.1] & $2^{\mathrm{e}-11}$ \\
\hline GBAJ01000049 & BP10 & & $1^{\mathrm{e}-11}$ \\
\hline GBAI01000033 & BP6 & conserved hypothetical protein Ixodes scapularis [XP_002404412.1] & $3^{e-07}$ \\
\hline GBAI01000037 & BP6 & conserved protein 364 Amblyomma variegatum [DAA34231.1] & $2^{\mathrm{e}-12}$ \\
\hline \multirow[t]{4}{*}{ GBAI01000051 } & BP6 & hypothetical secreted protein 1652 Amblyomma variegatum [DAA34045.1] & $2^{\mathrm{e}-45}$ \\
\hline & & putative salivary secreted protein Ixodes scapularis [AAY66581.1] & $4^{\mathrm{e}-45}$ \\
\hline & & salivary protein antigen P23 Ixodes scapularis (AEE89467.1, $2^{\mathrm{e}-38}$ ) & $1^{e-41}$ \\
\hline & & secreted salivary gland peptide Ixodes scapularis [XP_002435217.1] & $2^{e-38}$ \\
\hline GBAI01000092 & BP6 & conserved hypothetical protein, mRNA Ixodes scapularis [XM_002413966.1] ${ }^{1}$ & $5^{\mathrm{e}-40}$ \\
\hline GBAI01000096 & BP6 & conserved hypothetical protein Ixodes scapularis [XP_002414011.1] & $1^{\mathrm{e}-80}$ \\
\hline GBAI01000102 & BP6 & hypothetical protein Haemaphysalis longicornis [BAE02551.1] & $7^{\mathrm{e}-07}$ \\
\hline GBAK01000356 & BP13-14 & & $3^{e-05}$ \\
\hline \multirow[t]{2}{*}{ GBAI01000061 } & BP6 & putative cement protein Amblyomma variegatum [BK007766.1] & $4^{e-04}$ \\
\hline & & conserved hypothetical protein, mRNA Ixodes scapularis [XM_002400050.1] & 0.3 \\
\hline GBAJ01000018 & BP10 & & 0.36 \\
\hline GBAK01000332 & BP13-14 & & 0.37 \\
\hline GBAL01000162 & BP15-16 & & 0.091 \\
\hline GBAJ01000021 & $\mathrm{BP} 10$ & conserved hypothetical protein Ixodes scapularis [XP_002403158.1] & $2^{e-56}$ \\
\hline GBAJ01000051 & BP10 & hypothetical protein IscW_ISCW013255 Ixodes scapularis [XM_002413442.1] & $6^{\mathrm{e}-91}$ \\
\hline GBAK01000272 & BP13-14 & putative cement protein Amblyomma variegatum [DAA34732.1] & $4^{e-12}$ \\
\hline GBAJ01000077 & BP10 & & $3^{e-04}$ \\
\hline GBAJ01000078 & BP10 & hypothetical protein Haemaphysalis longicornis [BAE02552.1] & $3^{e-10}$ \\
\hline GBAJ01000079 & BP10 & & $2^{\mathrm{e}-08}$ \\
\hline GBAK01000069 & BP13-14 & & $4^{\mathrm{e}-08}$ \\
\hline
\end{tabular}




\section{Table 2 Amblyomma americanum tick saliva proteins encoding cDNAs conserved in other tick species, but not} in mammals (Continued)

\begin{tabular}{|c|c|c|c|}
\hline GBAJ01000086 & BP10 & conserved hypothetical protein Ixodes scapularis [XP_002399913.1] & $3^{\mathrm{e}-41}$ \\
\hline GBAK01000083 & BP13-14 & secreted salivary gland peptide, putative Ixodes scapularis [XM_002412128.1] & $2^{e^{-18}}$ \\
\hline GBAJ01000091 & BP10 & & $6^{\mathrm{e}-22}$ \\
\hline GBAJ01000099 & BP10 & hypothetical secreted protein 123 mRNA, complete cds Amblyomma americanum [BK007643.1] & $1^{\mathrm{e}-10}$ \\
\hline GBAK01000035 & BP13-14 & hypothetical protein IscW_ISCW001430 Ixodes scapularis [XP_002401466.1] & $1^{\mathrm{e}-04}$ \\
\hline GBAK01000049 & BP13-14 & mucin peritrophin salivary protein Amblyomma variegatum [DAA34644.1] & $3^{\mathrm{e}-05}$ \\
\hline GBAK01000045 & BP13-14 & hypothetical protein IscW_ISCW000843 Ixodes scapularis [XP_00240030.1] & $3^{\mathrm{e}-39}$ \\
\hline GBAL01000114 & BP15-16 & & $1^{\mathrm{e}-48}$ \\
\hline GBAK01000058 & BP13-14 & Ixodes scapularis hypothetical protein, mRNA Ixodes scapularis [XM_002412067.1] & $4^{\mathrm{e}-21}$ \\
\hline GBAK01000062 & BP13-14 & conserved hypothetical protein, mRNA Ixodes scapularis [XM_002411503.1] & $2^{\mathrm{e}-27}$ \\
\hline GBAK01000109 & BP13-14 & hypothetical protein IscW_ISCW01 1068 Ixodes scapularis [XP_002411440.1] & $9^{e-06}$ \\
\hline GBAK01000119 & BP13-14 & conserved hypothetical protein Ixodes scapularis [XP_002416006.1] & $1^{\mathrm{e}-08}$ \\
\hline GBAK01000123 & BP13-14 & hypothetical protein, mRNA Ixodes scapularis [XM_002436116.1] & $3^{\mathrm{e}-07}$ \\
\hline GBAK01000138 & BP13-14 & hypothetical protein Haemaphysalis longicornis [BAE02708.1] & $8^{\mathrm{e}-07}$ \\
\hline GBAK01000161 & BP13-14 & hypothetical protein, mRNA Ixodes scapularis [XM_002400149.1] & $3^{\mathrm{e}-07}$ \\
\hline GBAK01000165 & BP13-14 & conserved hypothetical protein Ixodes scapularis [XP_002435325.1] & $1^{\mathrm{e}-27}$ \\
\hline GBAK01000185 & BP13-14 & hypothetical protein IscW_ISCW024828 Ixodes scapularis [XP_002416135.1] & $7^{\mathrm{e}-06}$ \\
\hline \multirow[t]{2}{*}{ GBAK01000195 } & BP13-14 & secreted PAPA repeat protein Amblyomma variegatum [DAA34610.1] & $1^{\mathrm{e}-04}$ \\
\hline & & hypothetical protein Ixodes scapularis [(XP_002433942.1] & $6^{\mathrm{e}-07}$ \\
\hline GBAK01000417 & BP13-14 & conserved hypothetical protein Ixodes scapularis [XP_002434340.1] & $1^{\mathrm{e}-10}$ \\
\hline GBAK01000238 & BP13-14 & conserved hypothetical protein Ixodes scapularis [XP_002403178.1] & $1^{\mathrm{e}-118}$ \\
\hline GBAK01000260 & BP13-14 & hypothetical secreted protein 94 Amblyomma variegatum [DAA34289.1] & $4^{e-08}$ \\
\hline GBAK01000306 & BP13-14 & hypothetical protein IscW_ISCW024139 Ixodes scapularis [XP_002408992.1] & $9^{e-44}$ \\
\hline GBAL01000156 & BP15-16 & & $1^{e-37}$ \\
\hline GBAK01000322 & BP13-14 & conserved hypothetical protein Ixodes scapularis [XP_002399367.1] & $4^{e-61}$ \\
\hline \multirow[t]{2}{*}{ GBAK01000324 } & BP13-14 & cuticle protein 10.9 Ixodes ricinus [P84251.1] & $1^{e-39}$ \\
\hline & & secreted salivary gland peptide Ixoders scapularis [XP_002407787.1] & $2^{\mathrm{e}-39}$ \\
\hline GBAK01000338 & BP13-14 & conserved hypothetical protein Ixodes scapularis [XM_002412107.1] & $1^{e-77}$ \\
\hline GBAK01000367 & BP13-14 & hypothetical protein IscW_ISCW001471 Ixodes scapularis [XM_002399258.1] & $1^{\mathrm{e}-26}$ \\
\hline GBAL01000163 & BP15-16 & & $3^{e-41}$ \\
\hline GBAK01000374 & BP13-14 & hypothetical protein IscW_ISCW002509 Ixodes scapularis [XP_002403210.1] & $5^{\mathrm{e}-15}$ \\
\hline GBAK01000408 & BP13-14 & CDC73 protein, putative Ixodes scapularis [XP_002410866.1] & $3^{e-46}$ \\
\hline GBAK01000350 & BP13-14 & conserved hypothetical protein Ixodes scapularis [XP_002400434.1] ${ }^{2}$ & $4^{e-61}$ \\
\hline GBAK01000378 & BP13-14 & putative secreted salivary protein Ixodes scapularis [AAY66509.1] & $4^{e-09}$ \\
\hline GBAL01000023 & BP15-16 & conserved hypothetical protein Ixodes scapularis [XM_002411217.1] & $6^{\mathrm{e}-24}$ \\
\hline GBAL01000028 & BP15-16 & conserved hypothetical protein Ixodes scapularis [XP_002404724.1] & $1^{\mathrm{e}-27}$ \\
\hline GBAL01000035 & BP15-16 & putative secreted salivary protein Ixodes scapularis [AAY6670.1] & $6^{e^{-17}}$ \\
\hline \multirow[t]{2}{*}{ GBAL01000036 } & BP15-16 & putative salivary secreted peptide Ixodes pacificus [AAT92118.1] & $8^{e-35}$ \\
\hline & & secreted salivary gland peptide, putative Ixodes scapularis [XP_002433339.1] & $7^{e^{-34}}$ \\
\hline GBAL01000048 & BP15-16 & conserved hypothetical protein Ixodes scapularis [XM_002407819.1] & $1^{\mathrm{e}-09}$ \\
\hline GBAK01000098 & BP13-14 & & $1^{\mathrm{e}-09}$ \\
\hline GBAL01000057 & BP15-16 & conserved hypothetical protein Ixodes scapularis [XM_002409429.1] & $2^{\mathrm{e}-09}$ \\
\hline GBAL01000078 & BP15-16 & conserved hypothetical protein Ixodes scapularis [XM_002415769.1] & 0.008 \\
\hline GBAL01000118 & BP15-16 & putative cement protein mRNA, complete cds Amblyomma variegatum [BK007766.1] & $6^{\mathrm{e}-35}$ \\
\hline
\end{tabular}




\begin{tabular}{|c|c|c|c|}
\hline GBAL01000126 & BP15-16 & conserved hypothetical protein Ixodes scapularis [XP_002406503.1] & $3^{e^{-74}}$ \\
\hline GBAL01000148 & BP15-16 & conserved hypothetical protein Ixodes scapularis [XP_002413922.1] & $2^{\mathrm{e}-76}$ \\
\hline GBAL01000168 & BP15-16 & clone HqL09 unknown mRNA Haemaphysalis qinghaiensis [EF605265.1] & $9^{e-19}$ \\
\hline GBAL01000169 & BP15-16 & hypothetical protein IscW_ISCW007130 Ixodes scapularis [XP_002403722.1] & $3^{\mathrm{e}-13}$ \\
\hline GBAL01000181 & BP15-16 & ubiquitously expressed transcript (UXT), putative Ixodes scapularis [XP_002410385.1] & $5^{e-56}$ \\
\hline GBAL01000185 & BP15-16 & conserved hypothetical protein Ixodes scapularis [XP_002400069.1] & $6^{\mathrm{e}-05}$ \\
\hline GBAL01000196 & BP15-16 & hypothetical protein IscW_ISCW011816 Ixodes scapularis [XP_002412243.1] & $2^{\mathrm{e}-10}$ \\
\hline GBAL01000210 & BP15-16 & secreted protein, putative Ixodes scapularis [XP_002401383.1] & $1^{\mathrm{e}-27}$ \\
\hline GBAL01000221 & BP15-16 & secreted salivary gland peptide, putative Ixodes scapularis [XP_002401305.1] & $1^{\mathrm{e}-22}$ \\
\hline GBAL01000247 & BP15-16 & hypothetical protein IscW_ISCW011424 Ixodes scapularis [XP_002412199.1] & $3^{\mathrm{e}-16}$ \\
\hline GBAL01000249 & BP15-16 & secreted salivary gland peptide, putative Ixodes scapularis [XP_002414543.1] & $4^{e-06}$ \\
\hline \multirow[t]{2}{*}{ GBAL01000252 } & BP15-16 & secreted protein, putative Ixodes scapularis [XP_002408033.1] & 0.29 \\
\hline & & glycine rich protein 44 Amblyomma variegatum [DAA34246.1] & 0.98 \\
\hline GBAL01000253 & BP15-16 & 65-kDa macrophage protein, putative Ixodes scapularis [XP_002413054.1] & $2^{\mathrm{e}-42}$ \\
\hline GBAL01000255 & BP15-16 & conserved hypothetical protein Ixodes scapularis [XM_002433956.1] & $3^{\mathrm{e}-42}$ \\
\hline GBAL01000260 & BP15-16 & conserved hypothetical protein Ixodes scapularis [XM_002435514.1] & $1^{\mathrm{e}-36}$ \\
\hline
\end{tabular}

${ }^{1}$ show conservation in mammals.

${ }^{2}$ highly identical to apoptosis response protein.

[75] contains sequences which show a high level of identity to GBAI01000007, GBAI01000051, GBAK01000417, GBAK01000324, and GBAK01000378 sequences related to immunogenic hypothetical $A$. americanum proteins. Highly conserved proteins such as AV422, and others described here could represent important target antigens for the development of universal anti-tick vaccines, which are highly advocated for [30]. Male biopanned library originating sequence GBAL01000253 showed 80\% amino acid sequence identity with putative I. scapularis $65 \mathrm{kDa}$ macrophage protein. The role(s) of its intracellular mammalian ortholog is poorly understood, but a predicted phosphorylation site and a series of $\mathrm{Ca}^{2+}$ binding domains indicate that this protein could be involved in processes determining macrophage activity in immune response [76].

\section{A. americanum tick saliva immunogenic proteases}

Proteases are central to the physiology of all organisms. In tick physiology, proteases were linked to embryo development [77,78], blood meal feeding [79], and host blood processing in the midgut [80]. Interfering with tick protease function, as revealed by RNAi silencing $[81,82]$, and feeding of ticks on animals immunized with recombinant proteases [83], affected tick feeding efficiency and reproduction. Here for the first time, we indicate that some protease-like molecules including Leukotriene A-4 hydrolase (LTA4H), asparaginyl endopeptidase, cysteine proteinases, carboxy- and metallo-proteases, as well as ubiquitin fusion degradation protein, are present in $A$. americanum tick saliva at the beginning of the tick feeding process (Table 3 ).

The presence of LTA4H in A. americanum is interesting and counter-intuitive. In mammals, the LTA4H enzyme catalyzes the last step in biosynthesis of leukotriene B4 (LTB4), a potent chemo attractant and proinflammatory lipid mediator derived from arachidonic acid $[84,85]$ that is involved in immune responses [86], host defense against infection [87], platelet activation [88], and lipid metabolism [89]. The pro-host defense functions of LTA4H are contrary to what the tick is expected to do to accomplish feeding, to block inflammation and other host defense mechanisms. From this perspective, it will be interesting to investigate if $A$. americanum LTA4H is functional. There is a possibility that $A$. americanum LTA4H performs other functions at the tick-feeding site.

Of the 18 sequences in Table 3 , six sequences GBAI01000024, GBAJ01000008, GBAK01000094, GBA K01000180, GBAK01000182 and GBAK01000183 are provisionally identified as cathepsin-like cysteine proteases. Accumulating evidence suggests that secretion of cysteine proteases in A. americanum tick saliva is relatable to tick and host interactions. In mammals, cathepsin $\mathrm{B}$ and $\mathrm{L}$ are ubiquitously expressed and multifunctional, intracellular and extracellular [90]. They are involved with protein turnover housekeeping function in lysosomes [91], degradation of extracellular matrix [92], elimination of cellular mediators of inflammation such as neutrophils [93], and recent studies have demonstrated extracellular activity of human cathepsin B and L associated with inflammation 
Table 3 Putative proteases in Amblyomma americanum tick saliva

\begin{tabular}{|c|c|c|c|}
\hline Accession\# & Source library & Top matches in GenBank [accession\#] & e-values \\
\hline GBAK01000372 & BP13-14 & putative legumain-like protease precursor Dermacentor variabilis [ACF35522.1] & $3^{\mathrm{e}-47}$ \\
\hline \multirow[t]{2}{*}{ GBAI01000003 } & BP6 & protease, putative Ixodes scapularis [XP_002413749.1] & $4^{\mathrm{e}-40}$ \\
\hline & & leukotriene hydrolase Argas monolakensis [ABI52802.1] & $4^{e-32}$ \\
\hline \multirow[t]{2}{*}{ GBAJ01000102 } & $\mathrm{BP} 10$ & protease, putative Ixodes scapularis [XP_002413749.1] & $2^{\mathrm{e}-26}$ \\
\hline & & leukotriene hydrolase Argas monolakensis [ABI52802.1] & $3^{\mathrm{e}-21}$ \\
\hline \multirow[t]{2}{*}{ GBAK01000094 } & BP13-14 & putative cathepsin B-like cysteine protease form 1 Dermacentor variabilis [ACF35525.1] & $5^{\mathrm{e}-60}$ \\
\hline & & cathepsin B-like cysteine protease form 1 Ixodes ricinus [ABO26563.1] & $3^{e-56}$ \\
\hline GBAI01000024 & BP6 & cathepsin L-like cysteine proteinase A Rhipicephalus haemaphysaloides haemaphysaloides [AAQ16117.1] & $3^{\mathrm{e}-14}$ \\
\hline GBAJ01000008 & BP10 & & $2^{\mathrm{e}-82}$ \\
\hline GBAK01000180 & BP13-14 & & $3^{\mathrm{e}-28}$ \\
\hline GBAK01000182 & BP13-14 & Longipain Haemaphysalis longicornis [BAF43801.1] & $4^{e-55}$ \\
\hline GBAK01000183 & BP13-14 & & $7^{\mathrm{e}-41}$ \\
\hline \multirow[t]{2}{*}{ GBAK01000214 } & BP13-14 & conserved hypothetical protein Ixodes scapularis [XP_002414190.1] & $7^{\mathrm{e}-15}$ \\
\hline & & serine carboxypeptidase, putative Ixodes scapularis [XP_002403464.1] & $2^{\mathrm{e}-12}$ \\
\hline \multirow[t]{2}{*}{ GBAL01000134 } & BP15-16 & conserved hypothetical protein Ixodes scapularis [XP_002414190.1] & $2^{\mathrm{e}-13}$ \\
\hline & & serine carboxypeptidase, putative Ixodes scapularis [XP_002414193.1] & $8^{\mathrm{e}-11}$ \\
\hline GBAJ01000040 & BP10 & serine carboxypeptidase, putative Ixodes scapularis [XP_002403464.1] & $2^{\mathrm{e}-14}$ \\
\hline GBAK01000358 & BP13-14 & angiotensin-converting enzyme, putative Ixodes scapularis [XP_002401260.1] & $2^{\mathrm{e}-40}$ \\
\hline GBAK01000026 & BP13-14 & neprilysin, putative Ixodes scapularis [XP_002404392.1] & $1^{e-42}$ \\
\hline GBAK01000196 & BP13-14 & neprilysin, putative Ixodes scapularis [XP_002414107.1] & $1^{\mathrm{e}-05}$ \\
\hline GBAK01000111 & BP13-14 & metallopeptidase Amblyomma variegatum [DAA34047.1] & $4^{e-81}$ \\
\hline \multirow[t]{3}{*}{ GBAK01000132 } & BP13-14 & metalloprotease Haemaphysalis longicornis [BAE72664.1] & $3^{\mathrm{e}-06}$ \\
\hline & & metalloprotease, putative Ixodes scapularis [XP_002407430.1] & $4^{e-06}$ \\
\hline & & metalloprotease Argas monolakensis [ABI52779.1] & $3^{e-04}$ \\
\hline GBAK01000269 & BP13-14 & ubiquitin fusion-degradation protein, putative Ixodes scapularis [XP_002414671.1] & $5^{\mathrm{e}-62}$ \\
\hline
\end{tabular}

function [94]. Ticks are pool feeders that accomplish feeding by disrupting host tissue and sucking up the blood that bleeds into the wound [95]. This feeding style is expected to provoke host tissue repair response, to which inflammation and extracellular matrix modeling are important $[96,97]$. Thus, if functional, it is conceivable that tick saliva cathepsin B and L-like cysteine proteases could speculatively disrupt tissue repair response by killing cellular mediators of inflammation and destroying the extracellular matrix. There is indirect evidence for other parasites that show cysteine proteases as major components of the parasitic excretory-secretory immunoproteome in Spirometra mansoni [98] and Euclinostomum heterostomum [99]. In related studies Fasciola hepatica secretes a cathepsin-L protease linked to invasion of host tissue by this parasite [100], while application of cysteine protease inhibitors had anti-parasitic effects against Chagas' disease [101] and malaria [102] parasites. A lone study showed that $H$. longicornis cathepsin-L like cysteine protease, longipain displayed babesiacidal activity via specific adherence to the parasite membranes [103], which could indicate a role for cysteine proteases in tick immunity. Recently, $R$. microplus proteome analysis [75] revealed the presence of cathepsin-like cysteine protease sequence which appeared similar to GBAK01000094, GBAK0100 0182 and GBAK01000183 sequences described in this study.

In Table 3 we also listed sequence GBAK01000372, which showed identity to putative legumain-like protease precursor in $D$. variabilis. Legumain is a lysosomal cysteine protease that has a strict specificity for hydrolysis of asparaginyl bonds [104]. In human trematode parasite of blood vessels Schistosoma mansoni, this protease plays an important role in host hemoglobin degradation to diffusible peptides [105]. The same role is predicted for tick legumains found in the gut of $H$. longicornis [106] and Ixodes ricinus [107], as well as in sialotranscriptome analyses of Amblyomma maculatum [108].

Three sequences in Table 3, GBAJ01000040, GBA K01000214, and GBAL01000134 are provisionally identified as serine carboxypeptidases. Very little is known on serine carboxypeptidases in tick physiology research. A 
Table 4 Putative protease inhibitors in Amblyomma americanum tick saliva

\begin{tabular}{|c|c|c|c|}
\hline Accession\# & Source library & Top matches in GenBank [accession\#] & e-values \\
\hline GBAI01000043 & BP6 & neutrophil elastase inhibitor Rhipicephalus microplus [ABH10604.1] & $2^{\mathrm{e}^{-14}}$ \\
\hline GBAI01000058 & BP6 & & $3^{\mathrm{e}-07}$ \\
\hline GBAJ01000027 & BP10 & & $2^{\mathrm{e}-14}$ \\
\hline GBAL01000059 & BP15-16 & & $9^{e^{-11}}$ \\
\hline GBAK01000097 & BP13-14 & hypothetical protein Haemaphysalis longicornis [BAE02553.1] & $2^{\mathrm{e}-12}$ \\
\hline GBAL01000201 & BP15-16 & & $3^{\mathrm{e}-12}$ \\
\hline GBAK01000040 & BP13-14 & Chymotrypsin-elastase inhibitor ixodidin Rhipicephalus microplus [P83516] & $2^{\mathrm{e}-06}$ \\
\hline GBAJ01000043 & BP10 & Kunitz-like protease inhibitor precursor Amblyomma variegatum [DAA34606.1] & $2^{\mathrm{e}-29}$ \\
\hline GBAK01000277 & BP13-14 & putative salivary protein with Kunitz domains Ixodes scapularis [AAY66736.1] & $4^{\mathrm{e}-04}$ \\
\hline GBAJ01000023 & BP10 & putative Kunitz-BPTI protein Dermacentor variabilis [ACF35511.1] & $1^{\mathrm{e}-13}$ \\
\hline GBAK01000091 & BP13-14 & & $2^{\mathrm{e}-13}$ \\
\hline GBAK01000073 & BP13-14 & Carboxypeptidase inhibitor Rhipicephalus bursa [Q5EPH2.1] & $3^{\mathrm{e}-33}$ \\
\hline GBAJ01000071 & BP10 & ATPase inhibitor, putative Ixodes scapularis [XP_002399280.1] & $5^{\mathrm{e}-29}$ \\
\hline GBAK01000345 & BP13-14 & & $9^{e-26}$ \\
\hline GBAK01000027 & BP13-14 & translation initiation inhibitor UK114/IBM1, putative Ixodes scapularis [XP_002434004.1] & $2^{\mathrm{e}-12}$ \\
\hline GBAL01000098 & BP15-16 & & $2^{\mathrm{e}^{-12}}$ \\
\hline \multirow[t]{3}{*}{ GBAK01000064 } & BP13-14 & cystatin Haemaphysalis longicornis [ABZ89554.1] & $2^{\mathrm{e}-63}$ \\
\hline & & cystatin Dermacentor silvarum [ADZ23478.1] & $4^{\mathrm{e}-62}$ \\
\hline & & cystatin 2c Rhipicephalus microplus [AGW80659.1] & $1^{\mathrm{e}-59}$ \\
\hline \multirow[t]{3}{*}{ GBAL01000180 } & BP15-16 & cystatin 2b Rhipicephalus microplus [AGW80658.1] & $3^{\mathrm{e}-51}$ \\
\hline & & gut cystatin Rhipicephalus appendiculatus [AGB35873.1] & $3^{e-51}$ \\
\hline & & putative secreted cystatin Dermacentor variabilis [ACF35514.1] & $3^{e-36}$ \\
\hline GBAL01000013 & BP15-16 & cystatin Haemaphysalis longicornis [ABV71390.1] & $8^{\mathrm{e}-14}$ \\
\hline
\end{tabular}

lone study characterized a $H$. longicornis tick serine carboxypeptidase that is predominantly expressed in midgut and up regulated in response to tick feeding with the yeast expressed recombinant protein cleaving substrates similar to those of human serine carboxypeptidase cathepsin A [109]. Indirect evidence in helminth parasites, Strongyloides ratti [110] and Angiostrongylus cantonensis [111], excretory-secretory proteomes suggests that serine carboxypeptidases are part of the protein complex that regulates helminth parasite and host interactions. The presence of serine carboxypeptidases in A. americanum tick saliva may indicate that similar to other parasites, ticks use this class of proteins to regulate tick-host interactions. It is notable that cathepsin $\mathrm{A}$, the mammalian serine carboxypeptidases, has been linked to vasodilation, with malfunctions or deficiencies of this protein causing vasoconstriction [112]. One of the host's defense mechanisms to the tick feeding style of lacerating host tissue is vasoconstriction. Could tick saliva serine carboxypeptidase be involved in mediating the tick's vasodilating function? On the other hand, sequence GBAK01000358 shows identity to angiotensin-converting enzyme, a carboxypeptidase responsible for converting angiotensin I to angiotensin II, which constricts the blood vessels [113].

Four of the 18 sequences in Table 3, GBAK01000026, GBAK01000111, GBAK01000132, and GBAK01000196 show identity to annotated tick metalloproteases, with the last sequence showing identity to I. scapularis endothelin-converting enzyme. Expression of metalloproteases in tick salivary glands has been widely reported [114-116], with RNAi silencing of some affecting tick feeding efficiency and fertility in $R$. microplus [117] and $I$. ricinus [118], while feeding ticks on rabbits immunized with a recombinant tick metalloprotease affected $H$. longicornis tick feeding efficiency [119]. In a lone study, an I. scapularis recombinant metalloprotease similar to reprolysin had gelatinase and fibrinolytic activities [120]. Preventing blood clotting is among the most important "must do's" for ticks to successfully feed. From this perspective it is possible that the four metalloproteases found in $A$. americanum tick saliva could play important roles in facilitating tick feeding. It is also interesting to note that excretory-secretory proteomes of several blood feeding and/or dwelling parasites such as Haemonchus contortus [121], Onchocerca volvulus [122], 
Table 5 Putative immunogenic binding proteins and transporters present in Amblyomma americanum tick saliva

\begin{tabular}{|c|c|c|c|}
\hline Accession\# & Source library & Top matches in GenBank [accession\#] & e-values \\
\hline GBAJ01000035 & BP10 & hemelipoglycoprotein precursor, mRNA, complete cds Dermacentor variabilis [DQ422963.1] & 0.085 \\
\hline GBAL01000006 & BP15-16 & heme lipoprotein precursor, mRNA, complete cds Amblyomma americanum [EF050790.3] & 0.43 \\
\hline GBAK01000315 & BP13-14 & & $4^{e-50}$ \\
\hline GBAI01000078 & BP6 & ferritin Amblyomma americanum [AAQ54708.1] & $7^{e-79}$ \\
\hline GBAJ01000036 & BP10 & & $3^{\mathrm{e}-61}$ \\
\hline GBAJ01000098 & BP10 & & $2^{\mathrm{e}-45}$ \\
\hline GBAK01000211 & BP13-14 & & $3^{\mathrm{e}-96}$ \\
\hline GBAL01000165 & BP15-16 & & $1^{\mathrm{e}-37}$ \\
\hline GBAJ01000019 & BP10 & ferritin Haemaphysalis longicornis [AAQ54713.1] & $2^{\mathrm{e}-17}$ \\
\hline GBAI01000083 & BP6 & calmodulin, putative Ixodes scapularis [XP_002404770.1] & $3^{\mathrm{e}-53}$ \\
\hline GBAJ01000110 & BP10 & & $7^{e-68}$ \\
\hline GBAK01000031 & BP13-14 & & $7^{e-78}$ \\
\hline GBAL01000053 & BP15-16 & & $1^{\mathrm{e}-77}$ \\
\hline GBAJ01000101 & BP10 & calreticulin (crt-1) mRNA, complete cds Amblyomma americanum [U07708.1] & $3^{\mathrm{e}-10}$ \\
\hline GBAK01000025 & BP13-14 & & $7^{e-25}$ \\
\hline GBAI01000101 & BP6 & calponin, putative Ixodes scapularis [XP_002402437.1] & $1^{\mathrm{e}-56}$ \\
\hline GBAL01000044 & BP15-16 & sarcoplasmic calcium-binding proteins II, III, and IV, putative Ixodes scapularis [XP_002434211.1] & $1^{\mathrm{e}-04}$ \\
\hline GBAK01000066 & BP13-14 & lipocalin Argas monolakensis [AB|152816.1] & 0.002 \\
\hline GBAK01000093 & BP13-14 & salivary lipocalin Amblyomma variegatum [DAA34666.1] & $3^{\mathrm{e}-06}$ \\
\hline GBAL01000248 & BP15-16 & & $1^{\mathrm{e}-07}$ \\
\hline GBAI01000035 & BP6 & salivary lipocalin Amblyomma variegatum [DAA34698.1] & $9^{e-30}$ \\
\hline GBAK01000144 & BP13-14 & & $2^{\mathrm{e}-05}$ \\
\hline GBAL01000122 & BP15-16 & & $4^{\mathrm{e}-04}$ \\
\hline GBAK01000151 & BP13-14 & serotonin and histamine binding protein Dermacentor reticulatus [AAL56644.1] & $7^{\mathrm{e}-19}$ \\
\hline GBAL01000133 & BP15-16 & lipocalin Argas monolakensis [ABI52807.1] & $6^{\mathrm{e}-10}$ \\
\hline GBAJ01000056 & BP10 & fatty acid-binding protein FABP Amblyomma variegatum [DAA34565.1] & $3^{\mathrm{e}-06}$ \\
\hline GBAL01000186 & BP15-16 & ATP binding protein, putative Ixodes scapularis [XP_002399785.1] & 0.49 \\
\hline GBAK01000068 & BP13-14 & GTP-binding protein, putative Ixodes scapularis [XP_002412036.1] & $1^{\mathrm{e}-07}$ \\
\hline GBAJ01000103 & BP10 & histidine triad (hit) protein, putative Ixodes scapularis [XP_002412911.1] & $6^{e-48}$ \\
\hline GBAL01000222 & BP15-16 & RNA-binding protein, putative Ixodes scapularis [XP_002410612.1] ${ }^{1}$ & 2.1 \\
\hline GBAL01000072 & BP15-16 & RNA-binding nuclear protein, putative Ixodes scapularis [XP_002413820.1] & $6^{e^{-10}}$ \\
\hline GBAL01000055 & BP15-16 & RNA recognition motif protein, putative Ixodes scapularis [XP_002411413.1] & $2^{\mathrm{e}-36}$ \\
\hline \multirow[t]{2}{*}{ GBAK01000395 } & BP13-14 & DNA-binding protein C1D Amblyomma variegatum [DAA34443.1] & $2^{\mathrm{e}-31}$ \\
\hline & & sun-cor steroid hormone receptor co-repressor, putative Ixodes scapularis [XP_002402463.1] & $4^{e-26}$ \\
\hline GBAK01000082 & BP13-14 & immunoglobulin G binding protein A Rhipicephalus appendiculatus [AAB68801.1] & $3^{e-58}$ \\
\hline GBAK01000159 & BP13-14 & & $9^{e-10}$ \\
\hline \multirow[t]{2}{*}{ GBAK01000246 } & BP13-14 & $\begin{array}{l}\text { insulin-like growth factor binding protein-related protein } 6 \text { long mRNA, complete cds } \\
\text { Amblyomma americanum [GU907779.1] }\end{array}$ & $1^{\mathrm{e}-49}$ \\
\hline & & $\begin{array}{l}\text { insulin-like growth factor binding protein-related protein } 6 \text { short mRNA, complete cds } \\
\text { Amblyomma americanum [GU907778.1] }\end{array}$ & $5^{e-46}$ \\
\hline GBAL01000113 & BP15-16 & Evasin-1 Rhipicephalus sanguineus [EOC8P7.1] & $6^{\mathrm{e}-08}$ \\
\hline GBAL01000188 & BP15-16 & actin-binding protein Sla2, putative Ixodes scapularis [XP_002434768.1] & $2^{\mathrm{e}-74}$ \\
\hline GBAK01000236 & BP13-14 & cyclophilin A Haemaphysalis longicornis [BAG41813.1] & $4^{e-81}$ \\
\hline GBAL01000024 & BP15-16 & & $4^{\mathrm{e}-81}$ \\
\hline GBAK01000404 & BP13-14 & monocarboxylate transporter, putative Ixodes scapularis [XP_002435530.1] & 0.003 \\
\hline
\end{tabular}


Table 5 Putative immunogenic binding proteins and transporters present in Amblyomma americanum tick saliva (Continued)

\begin{tabular}{|c|c|c|c|}
\hline GBAL01000241 & BP15-16 & phosphatidylcholine transfer protein, putative Ixodes scapularis [XP_002408227.1] & $4^{e^{-43}}$ \\
\hline GBAK01000116 & BP13-14 & translocon-associated complex TRAP, alpha subunit, putative Ixodes scapularis [XP_002413372.1] & 2.2 \\
\hline GBAL01000016 & BP15-16 & trafficking protein particle complex subunit 6B, putative Ixodes scapularis [XP_002402611.1] & $8^{e-54}$ \\
\hline GBAK01000379 & BP13-14 & & $9^{e-54}$ \\
\hline
\end{tabular}

${ }^{1}$ contain G patch domain.

A. cantonensis [123,124], Ancylostoma caninum [125], Ancylostoma ceylanicum [126], and Clonorchis sinensis [127] have metalloproteases, which regulate interactions of these parasites with their vertebrate hosts. It is also notable that metalloproteases are a major component of snake venom that is responsible for hemorrhage and may also interfere with the hemostatic system [128]. The occurrence of an endothelin-converting enzyme-like protein in tick saliva could be considered counterintuitive in that in mammals this protease is involved in proteolytic processing of endothelins, which are potent vasoconstrictor molecules [129]. Ticks feed over a long period of time, and thus to continue feeding, host blood vessels must stay dilated. With the help of endothelins, the host constricts its blood vessels in response to injury as occurs during tick feeding to prevent further blood loss. The tick overcomes this defense by secreting vasodilator molecules into the feeding site. From this perspective the observation of an endothelin-converting enzyme-like protein in $A$. americanum was surprising.

A lone sequence, GBAK01000269 showed similarity to ubiquitin fusion-degradation protein, a protease, which is involved in degradation of ubiquitin tagged proteins [130]. Apart from the annotated I. scapularis sequence in GenBank, the ubiquitin fusion-degradation protein appears to have not been studied prior to this report. Ubiquitin and ubiquitin fusion-degradation protein are part of the protein clearance system. It will be interesting to investigate if the ubiquitin fusion-degradation protein observed is functional. If so, could it be used by ticks to prematurely clear host defense factors? It is interesting to note that in addition to ubiquitin fusiondegradation protein in Table 3, we also observed that $A$. americanum secretes ubiquitin ligase as well as ubiquitin/ ribosomal protein S27a fusion protein (Tables 6 and 7) during feeding. Could it be that the tick uses its own ubiquitin and ubiquitin fusion-degradation protein to tag and trigger degradation of host defense factors?

\section{Protease inhibitors}

Secretion of protease inhibitors in tick saliva as observed is not surprising. Given that host defenses against parasites are predominantly mediated by proteases, it's widely hypothesized in parasite and host interaction studies that parasites including ticks could utilize protease inhibitors to evade host defenses [131,132]. Table 4 lists 19 sequences that have been provisionally identified as inhibitors, serine protease inhibitors (GBAI01000043, GBAI01 000058, GBAJ01000023, GBAJ01000027, GBAJ01000043, GBAK01000040, GBAK01000091, GBAK01000277, GBA K01000097, GBAL01000201 and GBAL01000059), cysteine protease inhibitors (GBAK01000064, GBAL010000 13, and GBAL01000180), tick carboxypeptidase inhibitor (GBAK01000073), ATPase inhibitor (GBAJ01000071 and GBAK01000345), and translation initiation inhibitor (GB AK01000027 and GBAL01000098). It is notable, but not surprising that more than half of inhibitors found in $A$. americanum saliva in this study are putative inhibitors of serine proteases. Serine proteases have the "lions share" as mediators of the host's defense pathway to tick feeding [132], and thus it is conceivable that the majority of inhibitors in tick saliva will target serine proteases. It is interesting to note that the majority of reported tick salivary gland or tick saliva protease inhibitors inhibit serine proteases or serine protease mediated pathways including elastase [52,133,134], trypsin [52,134,135], thrombin [135], factor Xa [135], blood clotting in general [52,135], and complement activation $[52,136]$. Mammalian cysteine proteases play important roles in mediating host defense reactions $[132,137]$, and thus it is logical that A. americanum may secrete cystatins, the cysteine protease inhibitors in its saliva. One of the three cystatins, GBAL01000180 show high amino acid identity to $R$. microplus cystatin (AGW80658.1), a validated functional inhibitor of mammalian cysteine proteases [138]. Likewise the tick carboxypeptidase inhibitor found in $A$. americanum tick saliva shows high amino acid identity to a functionally characterized homolog in $R$. bursa, which has fibrinolytic function suggesting that it plays roles in blood meal feeding [139]. Nucleotides ADP, ATP, and UTP released into the extracellular environment play roles in inflammation [140], and are powerful chemotactic stimuli for immune response cells [141], functions that must be blocked for the tick to successfully feed. There is a possibility that the ATPase inhibitor found in A. americanum tick saliva could participate in blocking extracellular ATP function and in so doing, allow the tick to evade host defense reactions. The occurrence of the translation initiation inhibitor in $A$. americanum tick saliva is intriguing. The general function of the 
Table 6 Putative immunogenic enzymes in Amblyomma americanum tick saliva

\begin{tabular}{|c|c|c|c|}
\hline Accession\# & Source library & Top matches in GenBank [accession\#] & e-values \\
\hline GBAI01000009 & BP6 & FoF1 ATPase subunit6 Amblyomma americanum [ABA19091.1] & $9^{e-57}$ \\
\hline GBAJ01000009 & BP10 & F1F0 ATP-synthase subunit Cf6, putative Ixodes scapularis [XP_002399676.1] & $8^{\mathrm{e}-55}$ \\
\hline GBAI01000048 & BP6 & & $7^{\mathrm{e}-46}$ \\
\hline GBAK01000355 & BP13-14 & vacuolar H + -ATPase V1 sector, subunit G, putative Ixodes scapularis [XP_002415521.1] & $1^{\mathrm{e}-43}$ \\
\hline GBAK01000200 & BP13-14 & ADP/ATP translocase Ixodes scapularis [AAY66969.1] & $9^{e^{-19}}$ \\
\hline GBAK01000110 & BP13-14 & inner mitochondrial membrane translocase TIM17-like protein, partial Ixodes scapularis [AAY66838.1] & $5^{e-40}$ \\
\hline GBAK01000320 & BP13-14 & mitochondrial malate dehydrogenase, partial Ixodes scapularis [AAY66975.1] & $3^{\mathrm{e}-34}$ \\
\hline GBAI01000028 & BP6 & C1-tetrahydrofolate synthase, putative Ixodes scapularis [XP_002401635.1] & $2^{\mathrm{e}-39}$ \\
\hline GBAK01000202 & BP13-14 & cytochrome oxidase subunit 1 Amblyomma americanum [ABA19092.1] & $4^{\mathrm{e}-74}$ \\
\hline GBAL01000140 & BP15-16 & & $5^{\mathrm{e}-43}$ \\
\hline GBAI01000098 & BP6 & COX1 gene product (mitochondrion) Bothriocroton concolor [YP_006234392.1] & $9^{\mathrm{e}-47}$ \\
\hline GBAI01000099 & BP6 & cytochrome c oxidase subunit I Rhipicephalus zambeziensis [AAG23880.1] & $2^{\mathrm{e}-40}$ \\
\hline GBAK01000263 & BP13-14 & cytochrome c oxidase subunit I Amblyomma limbatum [ACM17834.1] & $1^{\mathrm{e}-59}$ \\
\hline GBAL01000112 & BP15-16 & cytochrome oxidase subunit 1 Ixodes scapularis [ADO64507.1] & $6^{e-55}$ \\
\hline GBAL01000084 & BP15-16 & cytochrome c oxidase subunit I Rhipicephalus maculatus [AAG23878.1] & $4^{e-25}$ \\
\hline GBAL01000143 & BP15-16 & cytochrome oxidase subunit 2 Amblyomma americanum [ABA19093.1] & $2^{\mathrm{e}-42}$ \\
\hline GBAK01000067 & BP13-14 & & $3^{e-70}$ \\
\hline GBAK01000121 & BP13-14 & cytochrome oxidase subunit 3 Amblyomma americanum [ABA19094.1] & $1^{\mathrm{e}-68}$ \\
\hline GBAL01000031 & BP15-16 & & $9^{e-69}$ \\
\hline GBAK01000343 & BP13-14 & cytochrome c oxidase polypeptide IV Ixodes scapularis [AAY66918.1] & $3^{e-55}$ \\
\hline GBAK01000282 & BP13-14 & cytochrome c oxidase polypeptide Vb Ixodes scapularis [AAY66932.1] & $2^{e-37}$ \\
\hline GBAJ01000050 & BP10 & cytochrome C oxidase, subunit VIb/COX12, putative Ixodes scapularis [XP_002416556.1] & $1^{\mathrm{e}-07}$ \\
\hline GBAK01000008 & BP13-14 & cytochrome oxidase subunit VIlc Ixodes pacificus [AAT92215.1] & $2^{\mathrm{e}-32}$ \\
\hline GBAJ01000041 & BP10 & ubiquinol cytochrome c reductase subunit QCR7 Amblyomma variegatum [DAA34591.1] & $7^{\mathrm{e}-52}$ \\
\hline GBAK01000326 & BP13-14 & & $4^{\mathrm{e}-47}$ \\
\hline GBAJ01000024 & BP10 & NADH:ubiquinone oxidoreductase, NDUFS2/49 kDa subunit, putative Ixodes scapularis [XP_002404495.1] & $3^{e-82}$ \\
\hline GBAJ01000104 & BP10 & NADH-ubiquinone oxidoreductase ashi subunit, putative Ixodes scapularis [XP_002409125.1] & $2^{\mathrm{e}-08}$ \\
\hline GBAK01000386 & BP13-14 & estradiol 17-beta-dehydrogenase, putative Ixodes scapularis [XP_002434666.1] & $5^{e-33}$ \\
\hline GBAL01000014 & BP15-16 & NADH dehydrogenase subunit 1 (mitochondrion) Amblyomma cajennense [YP_007475022.1] & $3^{e-40}$ \\
\hline GBAK01000139 & BP13-14 & NADH dehydrogenase subunit 2 Amblyomma americanum [ABA19096.1] & $3^{\mathrm{e}-10}$ \\
\hline GBAK01000133 & BP13-14 & NADH dehydrogenase subunit 3 (mitochondrion) Amblyomma cajennense [YP_007475021.1] & $5^{\mathrm{e}-27}$ \\
\hline GBAL01000089 & BP15-16 & NADH dehydrogenase subunit 4 Amblyomma americanum [ABA19099.1] & $3^{e-33}$ \\
\hline \multirow[t]{2}{*}{ GBAI01000088 } & BP6 & alkyl hydroperoxide reductase, thiol specific antioxidant, putative Ixodes scapularis [XP_002405466.1] & $2^{\mathrm{e}-42}$ \\
\hline & & thioredoxin peroxidase Ornithodoros parkeri [ABR23404.1] & $1^{\mathrm{e}-41}$ \\
\hline GBAL01000174 & BP15-16 & peroxidase, putative Ixodes scapularis [XP_002404935.1] & $1^{\mathrm{e}-34}$ \\
\hline GBAL01000029 & BP15-16 & thioredoxin reductase, putative Ixodes scapularis [XP_002404402.1] & $1^{e-68}$ \\
\hline GBAI01000050 & BP6 & putative glutathione S-transferase Dermacentor variabilis [ACF35539.1] & $4^{e-94}$ \\
\hline GBAK01000166 & BP13-14 & & $7^{\mathrm{e}-105}$ \\
\hline GBAL01000121 & BP15-16 & & $7^{\mathrm{e}-67}$ \\
\hline GBAL01000175 & BP15-16 & & $1^{\mathrm{e}-32}$ \\
\hline GBAK01000413 & BP13-14 & putative glutathione S-transferase Dermacentor variabilis [ACF35505.1] & $9^{e-32}$ \\
\hline GBAK01000042 & BP13-14 & gamma-glutamyltransferase, putative Ixodes scapularis [XP_002407102.1] & 0.006 \\
\hline GBAL01000137 & BP15-16 & & 0.006 \\
\hline GBAL01000157 & BP15-16 & protein disulfide isomerase Amblyomma variegatum [ABD16189.1] & 0 \\
\hline
\end{tabular}


Table 6 Putative immunogenic enzymes in Amblyomma americanum tick saliva (Continued)

\begin{tabular}{|c|c|c|c|}
\hline GBAK01000105 & BP13-14 & & 0 \\
\hline GBAK01000289 & BP13-14 & protein disulfide isomerase Amblyomma variegatum [DAA34067.1] & $4^{e-57}$ \\
\hline GBAI01000054 & BP6 & protein disulfide isomerase Haemaphysalis longicornis [ABS50238.1] & $1^{\mathrm{e}-24}$ \\
\hline GBAI01000015 & BP6 & protein disulfide isomerase-1 Haemaphysalis longicornis [BAF63672.1] & $9^{e-04}$ \\
\hline GBAK01000337 & BP13-14 & protein disulfide isomerase-2 Haemaphysalis longicornis [BAF63671.1] & $3^{\mathrm{e}-39}$ \\
\hline GBAI01000074 & BP6 & sulfotransferase, putative Ixodes scapularis [XP_002435996.1] & $9^{e^{-14}}$ \\
\hline GBAJ01000030 & $\mathrm{BP} 10$ & & $3^{\mathrm{e}-19}$ \\
\hline GBAL01000144 & BP15-16 & & 0.033 \\
\hline GBAJ01000034 & $\mathrm{BP} 10$ & sulfotransferase, putative Ixodes scapularis [XP_002436296.1] & $7^{e^{-14}}$ \\
\hline GBAL01000136 & BP15-16 & sulfotransferase, putative Ixodes scapularis [XP_002400534.1] & $3^{e-35}$ \\
\hline GBAK01000319 & BP13-14 & glycosyl transferase, putative Ixodes scapularis [XP_002434372.1] & $2^{\mathrm{e}-31}$ \\
\hline GBAK01000388 & BP13-14 & & $1^{\mathrm{e}-38}$ \\
\hline GBAK01000266 & BP13-14 & acyl-CoA synthetase, putative Ixodes scapularis [XP_002401840.1] & $2^{e^{-31}}$ \\
\hline GBAK01000079 & BP13-14 & adenylosuccinate lyase, putative Ixodes scapularis [XP_002399354.1] & $4^{e-34}$ \\
\hline GBAK01000191 & BP13-14 & casein kinase, putative Ixodes scapularis [XP_002400161.1] & $2^{\mathrm{e}-30}$ \\
\hline GBAL01000108 & BP15-16 & & $1^{\mathrm{e}-30}$ \\
\hline GBAK01000072 & BP13-14 & 3-hydroxyacyl-CoA dehydrogenase, putative Ixodes scapularis [XP_002415080.1] & $1^{\mathrm{e}-79}$ \\
\hline GBAI01000093 & BP6 & malonyl CoA-acyl carrier protein transacylase, putative Ixodes scapularis [XP_002402213.1] & $5^{\mathrm{e}-15}$ \\
\hline GBAI01000059 & BP6 & dihydrolipoamide acetyltransferase, putative Ixodes scapularis [XP_002401656.1] & $8^{e-05}$ \\
\hline \multirow[t]{2}{*}{ GBAJ01000090 } & $\mathrm{BP} 10$ & RAB GTPase-activating protein, putative Ixodes scapularis [XP_002407414.1] & $2^{\mathrm{e}-29}$ \\
\hline & & GTPase-activating protein Amblyomma variegatum [DAA34545.1] & $3^{e-27}$ \\
\hline GBAK01000234 & BP13-14 & ubiquitin protein ligase Ixodes scapularis [XP_002434331.1] & $2^{e-28}$ \\
\hline \multirow[t]{2}{*}{ GBAI01000014 } & BP6 & SCF ubiquitin ligase Skp1 component Amblyomma variegatum [DAA34559.1] & $2^{\mathrm{e}-46}$ \\
\hline & & SCF ubiquitin ligase complex Ixodes scapularis [AAY66893.1] & $2^{\mathrm{e}-46}$ \\
\hline GBAK01000329 & BP13-14 & phosphoribosylformylglycinamidine synthase, putative Ixodes scapularis [XP_002405859.1] & $2^{\mathrm{e}-35}$ \\
\hline \multirow[t]{2}{*}{ GBAK01000254 } & BP13-14 & lysine-ketoglutarate reductase/saccharopine dehydrogenase Haemaphysalis longicornis [BAI44335.1] & $6^{\mathrm{e}-77}$ \\
\hline & & lysine-ketoglutarate reductase, putative Ixodes scapularis [XP_002404033.1] & $3^{e-70}$ \\
\hline GBAK01000268 & BP13-14 & pterin-4-alpha-carbinolamine dehydratase, putative Ixodes scapularis [XP_002399841.1] & $1^{\mathrm{e}-56}$ \\
\hline GBAK01000157 & BP13-14 & ornithine aminotransferase, putative Ixodes scapularis [XP_002406120.1] & $2^{\mathrm{e}-45}$ \\
\hline GBAI01000082 & BP6 & methionyl-tRNA synthetase, putative Ixodes scapularis [XP_002433760.1] & $6^{e-32}$ \\
\hline GBAK01000365 & BP13-14 & aspartyl-tRNA synthetase, putative Ixodes scapularis [XP_002404413.1] & $6^{e-39}$ \\
\hline GBAL01000251 & BP15-16 & cysteine synthase, putative Ixodes scapularis [XP_002415219.1] & $3^{\mathrm{e}-39}$ \\
\hline GBAL01000103 & BP15-16 & ng,ng-dimethylarginine dimethylaminohydrolase, putative, mRNA Ixodes scapularis [XM_002404864.1] & $1^{\mathrm{e}-05}$ \\
\hline GBAL01000038 & BP15-16 & keratinocyte transglutaminase, putative Ixodes scapularis [XP_002402412.1] & $3^{e-46}$ \\
\hline GBAK01000354 & BP13-14 & & $2^{\mathrm{e}-36}$ \\
\hline GBAK01000325 & BP13-14 & lysosomal acid phosphatase Haemaphysalis longicornis [ADN34299.1] & $9^{e-66}$ \\
\hline GBAJ01000044 & BP10 & triosephosphate isomerase Rhipicephalus microplus [AFP81689.1] & $8^{\mathrm{e}-103}$ \\
\hline \multirow[t]{2}{*}{ GBAL01000080 } & BP15-16 & phosphoenolpyruvate carboxykinase Rhipicephalus microplus [ABO61883.1] & $2^{\mathrm{e}-36}$ \\
\hline & & phosphoenolpyruvate carboxykinase, putative Ixodes scapularis [XP_002404833.1] & $1^{\mathrm{e}-32}$ \\
\hline GBAK01000024 & BP13-14 & D-dopachrome tautomerase, putative Ixodes scapularis [XP_002401879.1] & $2^{\mathrm{e}-10}$ \\
\hline GBAJ01000109 & BP10 & transposase, putative Ixodes scapularis [XP_002415790.1] & $8^{\mathrm{e}-19}$ \\
\hline GBAI01000002 & BP6 & ribosomal protein S6 kinase, putative Ixodes scapularis [XP_002405308.1] & $3^{\mathrm{e}-21}$ \\
\hline
\end{tabular}


Table 7 Ribosomal proteins in Amblyomma americanum tick saliva

\begin{tabular}{|c|c|c|c|}
\hline Accession\# & Source library & Top matches in GenBank [accession\#] & e-values \\
\hline \multirow[t]{3}{*}{ GBAI01000031 } & BP6 & ribosomal protein Haemaphysalis qinghaiensis [ACD50888.1] & $2^{\mathrm{e}-37}$ \\
\hline & & ribosomal protein, putative Ixodes scapularis [XP_002400902.1] & $1^{\mathrm{e}-34}$ \\
\hline & & ribosomal protein, large P2 Ixodes pacificus [AAT92169.1] & $3^{\mathrm{e}-34}$ \\
\hline \multirow[t]{3}{*}{ GBAK01000179 } & BP13-14 & ribosomal protein Haemaphysalis qinghaiensis [ACD50888.1] & $2^{\mathrm{e}-39}$ \\
\hline & & ribosomal protein, putative Ixodes scapularis [XP_002400902.1] & $3^{\mathrm{e}-34}$ \\
\hline & & ribosomal protein, large P2 Ixodes pacificus [AAT92169.1] & $7^{e-34}$ \\
\hline GBAI01000107 & BP6 & 605 ribosomal protein L2/L8 Ornithodoros coriaceus [ACB70396.1] & $2^{\mathrm{e}-63}$ \\
\hline GBAK01000392 & BP13-14 & & $1^{\mathrm{e}-52}$ \\
\hline GBAI01000079 & BP6 & ribosomal protein L3, putative Ixodes scapularis [XP_002416193.1] & $6^{\mathrm{e}-73}$ \\
\hline GBAJ01000010 & BP10 & & $2^{\mathrm{e}-72}$ \\
\hline GBAK01000172 & BP13-14 & & $5^{\mathrm{e}-87}$ \\
\hline GBAL01000021 & BP15-16 & & $2^{\mathrm{e}-88}$ \\
\hline GBAL01000022 & BP15-16 & & $1^{\mathrm{e}-36}$ \\
\hline GBAL01000146 & BP15-16 & & $2^{\mathrm{e}-10}$ \\
\hline GBAI01000049 & BP6 & 605 ribosomal protein L5, putative Ixodes scapularis [XP_002434050.1] & $1^{\mathrm{e}-23}$ \\
\hline GBAJ01000073 & BP10 & 60 S ribosomal protein L9, putative Ixodes scapularis [XP_002407167.1] & $4^{e-118}$ \\
\hline GBAK01000059 & BP13-14 & & $3^{\mathrm{e}-48}$ \\
\hline GBAK01000198 & BP13-14 & ribosomal protein L9, putative Ixodes scapularis [XP_002433785.1] & $2^{\mathrm{e}-10}$ \\
\hline GBAJ01000084 & BP10 & 605 ribosomal protein L10a Ixodes scapularis [AAY66960.1] & $6^{\mathrm{e}-41}$ \\
\hline GBAK01000385 & BP13-14 & & $1^{\mathrm{e}-54}$ \\
\hline GBAL01000009 & BP15-16 & 605 ribosomal protein L10A, putative Ixodes scapularis [XP_002404773.1] & $3^{e-135}$ \\
\hline GBAJ01000105 & BP10 & 60 S ribosomal protein L10, putative Ixodes scapularis [XP_002399224.1] & $2^{e-56}$ \\
\hline GBAI01000057 & BP6 & ribosomal protein L11, putative Ixodes scapularis [XP_002409414.1] & $2^{\mathrm{e}-92}$ \\
\hline GBAK01000020 & BP13-14 & & $3^{e-125}$ \\
\hline GBAJ01000028 & BP10 & ribosomal protein L12 Dermacentor variabilis [ACF35542.1] & $1^{\mathrm{e}-102}$ \\
\hline GBAK01000299 & BP13-14 & putative 60 S ribosomal protein L13a Amblyomma maculatum [ADC97464.1] & $2^{-129}$ \\
\hline GBAJ01000052 & BP10 & putative 60 S ribosomal protein L13e Amblyomma americanum [ADC97461.1] & $2^{\mathrm{e}-97}$ \\
\hline GBAK01000188 & BP13-14 & 605 ribosomal protein L14, putative Ixodes scapularis [XP_002403086.1] & $4^{e-19}$ \\
\hline GBAL01000051 & BP15-16 & ribosomal protein L15, putative Ixodes scapularis [XP_002402071.1] & $8^{\mathrm{e}-51}$ \\
\hline GBAI01000047 & BP6 & ribosomal protein L17, putative Ixodes scapularis [XP_002435561.1] & $7^{e-100}$ \\
\hline GBAJ01000080 & BP10 & 605 ribosomal protein L17 Ixodes scapularis [Q4PM54.1] & $2^{\mathrm{e}-30}$ \\
\hline GBAK01000155 & BP13-14 & & $7^{\mathrm{e}-48}$ \\
\hline GBAI01000036 & BP6 & ribosomal protein L18a Ixodes scapularis [AAY66898.1] & $1^{e-115}$ \\
\hline GBAK01000375 & BP13-14 & & $1^{\mathrm{e}-32}$ \\
\hline GBAI01000086 & BP6 & ribosomal protein L19 Ixodes scapularis [AAY66930.1] & $3^{\mathrm{e}-10}$ \\
\hline GBAK01000273 & BP13-14 & & $3^{e-10}$ \\
\hline GBAI01000052 & BP6 & ribosomal protein L21, putative Ixodes scapularis [XP_002403588.1] & $3^{\mathrm{e}-87}$ \\
\hline GBAJ01000002 & BP10 & & $1^{\mathrm{e}-104}$ \\
\hline GBAK01000009 & BP13-14 & & $8^{\mathrm{e}-105}$ \\
\hline GBAL01000033 & BP15-16 & & $3^{\mathrm{e}-44}$ \\
\hline GBAI01000065 & BP6 & ribosomal protein L22, putative Ixodes scapularis [XP_002412444.1] & $5^{\mathrm{e}-47}$ \\
\hline GBAJ01000088 & BP10 & ribosomal protein L23 Haemaphysalis qinghaiensis [AAY42210.1] & $7^{e-69}$ \\
\hline GBAK01000232 & BP13-14 & & $3^{\mathrm{e}-29}$ \\
\hline GBAL01000079 & BP15-16 & 605 ribosomal protein L23 Ixodes scapularis [AAY66949.1] & $3^{\mathrm{e}-45}$ \\
\hline
\end{tabular}


Table 7 Ribosomal proteins in Amblyomma americanum tick saliva (Continued)

\begin{tabular}{|c|c|c|c|}
\hline GBAK01000114 & BP13-14 & 60S ribosomal protein L24, putative Ixodes scapularis [XP_002409587] & $2^{\mathrm{e}-32}$ \\
\hline GBAI01000006 & BP6 & ribosomal protein L26 Ixodes scapularis [AAY66956.1] & $6^{\mathrm{e}-62}$ \\
\hline GBAI01000053 & BP6 & ribosomal protein L27A, putative Ixodes scapularis [XP_002411588.1] & $3^{\mathrm{e}-72}$ \\
\hline GBAJ01000076 & BP10 & & $8^{\mathrm{e}-74}$ \\
\hline GBAJ01000039 & BP10 & 605 ribosomal protein L27, putative Ixodes scapularis [XP_002434022.1] & $2^{e-81}$ \\
\hline GBAK01000327 & BP13-14 & & $1^{\mathrm{e}-57}$ \\
\hline GBAI01000089 & BP6 & ribosomal protein L28, putative Ixodes scapularis [XP_002406865.1] & $2^{\mathrm{e}-40}$ \\
\hline GBAJ01000094 & $\mathrm{BP} 10$ & & $3^{e-39}$ \\
\hline GBAK01000004 & BP13-14 & & $4^{\mathrm{e}-19}$ \\
\hline GBAL01000085 & BP15-16 & & $6^{\mathrm{e}-40}$ \\
\hline GBAI01000022 & BP6 & 605 ribosomal protein L29 Ornithodoros parkeri [ABR23378.1] & $9^{e-27}$ \\
\hline GBAJ01000054 & BP10 & & $5^{\mathrm{e}-27}$ \\
\hline GBAK01000235 & BP13-14 & & $4^{\mathrm{e}-27}$ \\
\hline GBAL01000073 & BP15-16 & & $9^{e-27}$ \\
\hline GBAI01000080 & BP6 & ribosomal protein L30 Ixodes pacificus [AAT92174.1] & $2^{\mathrm{e}-77}$ \\
\hline GBAK01000061 & BP13-14 & & $6^{\mathrm{e}-72}$ \\
\hline \multirow[t]{3}{*}{ GBAI01000026 } & BP6 & ribosomal protein L31, putative Ixodes scapularis [XP_002403582.1] & $5^{\mathrm{e}-26}$ \\
\hline & & ribosomal protein L31 Dermacentor variabilis [ACF35537.1] & $6^{e-25}$ \\
\hline & & ribosomal protein L31 Argas monolakensis [ABI52770.1] & $1^{\mathrm{e}-23}$ \\
\hline \multirow[t]{3}{*}{ GBAK01000248 } & BP13-14 & ribosomal protein L31, putative Ixodes scapularis [XP_002403582.1] & $9^{e-15}$ \\
\hline & & ribosomal protein L31 Dermacentor variabilis [ACF35537.1] & $2^{\mathrm{e}-15}$ \\
\hline & & ribosomal protein L31 Argas monolakensis [ABI52770.1] & $3^{e^{-15}}$ \\
\hline \multirow[t]{3}{*}{ GBAK01000249 } & BP13-14 & ribosomal protein L31, putative Ixodes scapularis [XP_002403582.1] & $2^{\mathrm{e}-54}$ \\
\hline & & ribosomal protein L31 Dermacentor variabilis [ACF35537.1] & $1^{\mathrm{e}-57}$ \\
\hline & & ribosomal protein L31 Argas monolakensis [ABI52770.1] & $2^{\mathrm{e}-54}$ \\
\hline \multirow[t]{3}{*}{ GBAL01000017 } & BP15-16 & ribosomal protein L31, putative Ixodes scapularis [XP_002403582.1] & $1^{\mathrm{e}-68}$ \\
\hline & & ribosomal protein L31 Dermacentor variabilis [ACF35537.1] & $5^{\mathrm{e}-72}$ \\
\hline & & ribosomal protein L31 Argas monolakensis [ABI52770.1] & $1^{\mathrm{e}-68}$ \\
\hline GBAI01000075 & BP6 & $60 S$ ribosomal protein L32, putative Ixodes scapularis [XP_002399507.1] & $2^{\mathrm{e}-47}$ \\
\hline GBAK01000076 & BP13-14 & & $9^{e-57}$ \\
\hline GBAL01000139 & BP15-16 & & $4^{e-56}$ \\
\hline GBAL01000177 & BP15-16 & & $7^{e-25}$ \\
\hline GBAI01000067 & BP6 & ribosomal protein L34 Dermacentor variabilis [ACF35536.1] & $9^{e-60}$ \\
\hline GBAJ01000005 & BP10 & & $1^{\mathrm{e}-78}$ \\
\hline GBAJ01000007 & BP10 & & $7^{\mathrm{e}-74}$ \\
\hline GBAL01000158 & BP15-16 & & $4^{e-59}$ \\
\hline GBAK01000216 & BP13-14 & 60s ribosomal protein L34 Ornithodoros parkeri [ABR23475.1] & 0.079 \\
\hline GBAI01000084 & BP6 & 60 S ribosomal protein L35-like protein Dermacentor variabilis [ACF35541.1] & $1^{\mathrm{e}-50}$ \\
\hline GBAJ01000065 & BP10 & & $1^{\mathrm{e}-56}$ \\
\hline GBAL01000099 & BP15-16 & & $4^{\mathrm{e}-62}$ \\
\hline GBAI01000104 & BP6 & ribosomal protein L35a Ixodes scapularis [AAY66948.1] & $4^{e-54}$ \\
\hline GBAK01000296 & BP13-14 & & $4^{e-66}$ \\
\hline \multirow[t]{2}{*}{ GBAK01000203 } & BP13-14 & ribosomal protein L37A Ornithodoros parkeri [ABR23427.1] & $6^{e-58}$ \\
\hline & & ribosomal protein L37A Ixodes scapularis [AAY66836.1] & $6^{e-58}$ \\
\hline GBAI01000108 & BP6 & 605 ribosomal protein L37 Ixodes scapularis [AAY66940.1] & $5^{\mathrm{e}-41}$ \\
\hline
\end{tabular}


Table 7 Ribosomal proteins in Amblyomma americanum tick saliva (Continued)

\begin{tabular}{|c|c|c|c|}
\hline GBAJ01000022 & BP10 & & $2^{\mathrm{e}-43}$ \\
\hline GBAK01000262 & BP13-14 & & $7^{\mathrm{e}-20}$ \\
\hline GBAK01000291 & BP13-14 & ribosomal protein L39 Ixodes scapularis [AAY66991.1] & $8^{\mathrm{e}-30}$ \\
\hline GBAK01000220 & BP13-14 & ribosomal protein L40, putative Ixodes scapularis [XP_002401964.1] & $6^{\mathrm{e}-60}$ \\
\hline GBAI01000044 & BP6 & 605 ribosomal protein L44 Ornithodoros parkeri [ABR23416.1] & $1^{\mathrm{e}-54}$ \\
\hline GBAJ01000037 & BP10 & & $1^{\mathrm{e}-47}$ \\
\hline GBAK01000071 & BP13-14 & & $1^{\mathrm{e}-69}$ \\
\hline \multirow[t]{2}{*}{ GBAI01000068 } & BP6 & 40 S ribosomal protein S2/30S Ornithodoros parkeri [ABR23354.1] & $2^{\mathrm{e}-46}$ \\
\hline & & 405 ribosomal protein, putative Ixodes scapularis [XP_002400781.1] & $6^{\mathrm{e}-46}$ \\
\hline \multirow[t]{2}{*}{ GBAL01000191 } & BP15-16 & 40 S ribosomal protein S2/30S Ornithodoros parkeri [ABR23354.1] & $2^{e-58}$ \\
\hline & & $40 S$ ribosomal protein, putative Ixodes scapularis [XP_002400781.1] & $4^{e-59}$ \\
\hline GBAI01000001 & BP6 & 40S ribosomal protein S3 Ornithodoros parkeri [ABR23477.1] & $4^{\mathrm{e}-36}$ \\
\hline GBAJ01000042 & BP10 & & $2^{\mathrm{e}-36}$ \\
\hline GBAK01000305 & BP13-14 & & $2^{e-53}$ \\
\hline GBAK01000100 & BP13-14 & 40 S ribosomal protein S3a Amblyomma variegatum [DAA34106.1] & $3^{\mathrm{e}-92}$ \\
\hline GBAK01000101 & BP13-14 & 40 S ribosomal protein S3a Argas monolakensis [ABI52667.1] & $8^{\mathrm{e}-28}$ \\
\hline GBAL01000166 & BP15-16 & & $5^{\mathrm{e}-35}$ \\
\hline GBAK01000303 & BP13-14 & ribosomal protein S4 Ornithodoros parkeri [ABR23501.1] & $2^{e-50}$ \\
\hline GBAL01000235 & BP15-16 & $40 \mathrm{~S}$ ribosomal protein S4 Ixodes scapularis [Q4PMB3.1] & $6^{\mathrm{e}-78}$ \\
\hline GBAK01000108 & BP13-14 & 40S ribosomal protein S5 Dermacentor variabilis [AAO92286.1] & $2^{\mathrm{e}-143}$ \\
\hline \multirow[t]{2}{*}{ GBAK01000383 } & BP13-14 & truncated 40S ribosomal protein S7 Amblyomma variegatum [DAA34567.1] & $4^{\mathrm{e}-43}$ \\
\hline & & 40S ribosomal protein S7, putative Ixodes scapularis [XP_002405269.1] & $9^{\mathrm{e}-41}$ \\
\hline GBAK01000050 & BP13-14 & ribosomal protein S8, putative Ixodes scapularis [XP_002400259.1] & $1^{\mathrm{e}-106}$ \\
\hline GBAJ01000003 & BP10 & 40 S ribosomal protein S12 Dermacentor variabilis [AAP04352.1] & $2^{\mathrm{e}-91}$ \\
\hline GBAK01000242 & BP13-14 & & $7^{\mathrm{e}-80}$ \\
\hline GBAL01000145 & BP15-16 & & $1^{\mathrm{e}-91}$ \\
\hline GBAJ01000074 & BP10 & 40 S ribosomal protein S14, putative Ixodes scapularis [XP_002415092.1] & $5^{\mathrm{e}-57}$ \\
\hline GBAK01000028 & BP13-14 & & $2^{\mathrm{e}-82}$ \\
\hline GBAI01000064 & BP6 & ribosomal protein S15Aa Ixodes scapularis [AAY66923.1] & $3^{e-65}$ \\
\hline GBAJ01000026 & BP10 & & $3^{\mathrm{e}-63}$ \\
\hline GBAI01000097 & BP6 & 40 S ribosomal protein S15, putative Ixodes scapularis [XP_002406430.1] & $8^{\mathrm{e}-41}$ \\
\hline GBAJ01000100 & BP10 & & $1^{e-54}$ \\
\hline GBAK01000141 & BP13-14 & & $2^{\mathrm{e}-54}$ \\
\hline GBAL01000182 & BP15-16 & & $4^{\mathrm{e}-28}$ \\
\hline GBAI01000062 & BP6 & acidic ribosomal protein P0 Rhipicephalus microplus [AGQ49465.1] & $1^{\mathrm{e}-29}$ \\
\hline \multirow[t]{3}{*}{ GBAK01000283 } & BP13-14 & ribosomal protein S17 Dermacentor variabilis [ACF35534.1] & $3^{\mathrm{e}-59}$ \\
\hline & & ribosomal protein S17 Argas monolakensis [ABI52710.1] & $1^{\mathrm{e}-55}$ \\
\hline & & ribosomal protein S17, partial Ixodes scapularis [AAY66942.1] & $2^{\mathrm{e}-55}$ \\
\hline GBAI01000085 & BP6 & ribosomal protein S19, putative Ixodes scapularis [XP_002408352.1] & $1^{\mathrm{e}-38}$ \\
\hline GBAJ01000004 & BP10 & & $2^{e-25}$ \\
\hline GBAK01000158 & BP13-14 & & $2^{\mathrm{e}-97}$ \\
\hline \multirow[t]{2}{*}{ GBAI01000070 } & BP6 & ribosomal protein S20, putative Ixodes scapularis [XP_002405144.1] & $9^{e-58}$ \\
\hline & & ribosomal protein S20 Argas monolakensis [ABI52775.1] & $8^{\mathrm{e}-58}$ \\
\hline \multirow[t]{2}{*}{ GBAJ01000011 } & BP10 & ribosomal protein S20, putative Ixodes scapularis [XP_002405144.1] & $5^{e-59}$ \\
\hline & & ribosomal protein S20 Argas monolakensis [ABI52775.1] & $3^{\mathrm{e}-59}$ \\
\hline
\end{tabular}


Table 7 Ribosomal proteins in Amblyomma americanum tick saliva (Continued)

\begin{tabular}{|c|c|c|c|}
\hline \multirow[t]{2}{*}{ GBAK01000380 } & BP13-14 & ribosomal protein S20, putative Ixodes scapularis [XP_002405144.1] & $1^{e-52}$ \\
\hline & & ribosomal protein S20 Argas monolakensis [ABI52775.1] & $2^{e-51}$ \\
\hline GBAI01000045 & BP6 & 40 S ribosomal protein S21 Ixodes scapularis [Q4PM64.1] & $9^{\mathrm{e}-45}$ \\
\hline GBAJ01000020 & BP10 & & $1^{\mathrm{e}-51}$ \\
\hline GBAL01000117 & BP15-16 & & $7^{\mathrm{e}-44}$ \\
\hline GBAI01000103 & BP6 & 40 S ribosomal protein S23 Ixodes scapularis [Q86FP7.1] & $9^{e-60}$ \\
\hline GBAI01000056 & BP6 & ribosomal protein S24 Ixodes scapularis [AAY66904.1] & $2^{e-66}$ \\
\hline GBAJ01000083 & BP10 & & $4^{\mathrm{e}-69}$ \\
\hline GBAK01000149 & BP13-14 & ribosomal protein S24 Dermacentor variabilis [AAY40467.1] & $2^{\mathrm{e}-79}$ \\
\hline GBAL01000012 & BP15-16 & & $5^{\mathrm{e}-77}$ \\
\hline GBAK01000274 & BP13-14 & ribosomal protein S25 Ixodes scapularis [AAY66882.1] & $5^{\mathrm{e}-47}$ \\
\hline GBAK01000217 & BP13-14 & ubiquitin/ribosomal protein S27a fusion protein Dermacentor variabilis [ACF35544.1] & $1^{\mathrm{e}-79}$ \\
\hline GBAL01000172 & BP15-16 & & $8^{\mathrm{e}-32}$ \\
\hline GBAL01000116 & BP15-16 & ubiquitin/40S ribosomal protein S27a Ornithodoros parkeri [ABR23473.1] & $6^{\mathrm{e}-43}$ \\
\hline GBAK01000021 & BP13-14 & 40 S ribosomal protein S27 Ixodes scapularis [AAY66945.1] & $2^{\mathrm{e}-44}$ \\
\hline GBAL01000206 & BP15-16 & & $3^{\mathrm{e}-28}$ \\
\hline GBAL01000058 & BP15-16 & 40 S ribosomal protein S28 Ornithodoros parkeri [ABR23349.1] & $4^{\mathrm{e}-25}$ \\
\hline GBAI01000066 & BP6 & 40 S ribosomal protein S30 Ixodes scapularis [AAY66965.1] & $2^{\mathrm{e}-44}$ \\
\hline GBAK01000194 & BP13-14 & & $3^{e-65}$ \\
\hline GBAL01000160 & BP15-16 & & $4^{e-65}$ \\
\hline GBAK01000279 & BP13-14 & 605 acidic ribosomal protein P1, putative Ixodes scapularis [XP_002435967.1] & $3^{e-32}$ \\
\hline GBAK01000387 & BP13-14 & $20 S$ proteasome, regulatory subunit beta, putative Ixodes scapularis [XP_002406585.1] & $1^{\mathrm{e}-79}$ \\
\hline GBAI01000100 & BP6 & Mitochondrion 16S ribosomal RNA (16S rRNA) gene Amblyomma americanum [L34313.1] & $3^{\mathrm{e}-42}$ \\
\hline GBAK01000003 & BP13-14 & & $3^{e-68}$ \\
\hline GBAL01000010 & BP15-16 & & $3^{e-68}$ \\
\hline
\end{tabular}

translation initiation inhibitor is to disrupt synthesis of new proteins. The most immediate question is to test whether or not tick translation initiation inhibitor is functional, and if so does it internalize into host cells? If so does it block synthesis of new proteins at the tickfeeding site?

\section{A. americanum tick saliva transporters and/or ligand binding proteins}

We have provisionally identified A.americanum tick saliva transporters and/or binding proteins in Table 5 based on their putative ligand: iron and heme, calcium, immunoglobulin G, histamine, lipid and and/or fatty acid, actin, nucleic acid, insulin and miscellaneous. Except for proteins in the miscellaneous group, the occurrences of the majority of proteins in Table 5 are relatable to suspected molecular interactions between the host and the tick.

\section{Ferritin and hemelipoprotein}

Six and three sequences are provisionally identified as ferritin (GBAI01000078, GBAJ01000019, GBAJ01000036,
GBAJ01000098, GBAK01000111, and GBAL01000165) and hemelipoglycoprotein (HeLp) (GBAJ01000035, GBA K01000315, and GBAL01000006), respectively. Both ferritin [142-145] and HeLp [146,147] have been cloned and characterized in multiple tick species. During feeding and blood meal processing ticks are faced with the high risk of oxidative stress because of huge amounts of iron in host blood, and heme, a bi-product of hemoglobin digestion [148]. Although mechanisms need further clarification, ticks are protected against iron and heme mediated oxidative stress by ferritin [149] and HeLP [150]. Hajdusek et al. [149] proposed that ferritin bound host blood-derived iron, while HeLp bound heme and delivered it to tick tissues to meet cell requirements. The observation in this study that ticks inject ferritin and HeLp into the host during tick feeding raises an interesting question of whether or not the tick utilizes tick saliva ferritin and HeLp to dump iron and heme into the host to avoid oxidative stress. Tick secretion of ferritin and HeLp into the feeding-site could also benefit tick borne disease agents that may need iron and/or heme to proliferate [151,152]. Except 
Table 8 Putative immunogenic proteins of miscellaneous function in Amblyomma americanum tick saliva

\begin{tabular}{|c|c|c|c|}
\hline Accession\# & Source library & Top matches in GenBank [accession\#] & e-values \\
\hline GBAK01000340 & BP13-14 & transmembrane protein, putative Ixodes scapularis [XP_002406433.1] & $7^{e-30}$ \\
\hline GBAK01000341 & BP13-14 & & $1^{\mathrm{e}-12}$ \\
\hline GBAK01000135 & BP13-14 & signal sequence receptor beta Ixodes scapularis [XP_002414113.1] & $5^{\mathrm{e}-108}$ \\
\hline GBAL01000069 & BP15-16 & & $2^{\mathrm{e}-85}$ \\
\hline GBAK01000145 & BP13-14 & selenoprotein, putative Ixodes scapularis [XP_002400767.1] & $1^{\mathrm{e}-11}$ \\
\hline \multirow[t]{2}{*}{ GBAK01000160 } & BP13-14 & selenoprotein K, putative Ixodes scapularis [XP_002403087.1] & $1^{\mathrm{e}-06}$ \\
\hline & & selenoprotein K Amblyomma variegatum [DAA34408.1] & $2^{\mathrm{e}-06}$ \\
\hline GBAI01000072 & BP6 & salivary selenoprotein M precursor Ixodes scapularis [AAY66722.1] & $1^{\mathrm{e}-29}$ \\
\hline GBAK01000292 & BP13-14 & beta-actin mRNA, complete cds Dermacentor variabilis [EF488512.2] & $4^{e-13}$ \\
\hline GBAK01000044 & BP13-14 & $\begin{array}{l}\text { myosin heavy chain, skeletal muscle or cardiac muscle, putative } \\
\text { Ixodes scapularis [XP_002433460.1] }\end{array}$ & $8^{\mathrm{e}-60}$ \\
\hline GBAI01000046 & BP6 & myosin alkali light chain protein Haemaphysalis longicornis [ADN34300.1] & $2^{\mathrm{e}-41}$ \\
\hline GBAJ01000045 & BP10 & & $3^{e-35}$ \\
\hline GBAJ01000066 & BP10 & & $2^{\mathrm{e}-39}$ \\
\hline GBAK01000412 & BP13-14 & myosin light chain 1, putative Ixodes scapularis [XP_002414092.1] & $1^{\mathrm{e}-31}$ \\
\hline GBAK01000014 & BP13-14 & nonmuscle myosin essential light chain Ixodes scapularis [XP_002407055.1] & $1^{\mathrm{e}-97}$ \\
\hline GBAK01000264 & BP13-14 & paramyosin Haemaphysalis longicornis [AFR32950.1] & $3^{\mathrm{e}-45}$ \\
\hline GBAI01000090 & BP6 & beta-tubulin, putative Ixodes scapularis [XP_002403010.1] & $3^{e-10}$ \\
\hline \multirow[t]{2}{*}{ GBAK01000075 } & BP13-14 & dynein light chain Ixodes scapularis [XP_002408929.1] & $1^{\mathrm{e}-60}$ \\
\hline & & dynein light chain type 1 Rhipicephalus microplus [AHH29554.1] & $2^{\mathrm{e}-60}$ \\
\hline GBAJ01000053 & BP10 & zinc finger protein, putative Ixodes scapularis [XP_002413941.1] & $2^{\mathrm{e}-81}$ \\
\hline GBAK01000084 & BP13-14 & zinc finger protein, putative Ixodes scapularis [XP_002406104.1] & $1^{\mathrm{e}-28}$ \\
\hline GBAL01000027 & BP15-16 & & $8^{\mathrm{e}-29}$ \\
\hline GBAL01000011 & BP15-16 & zinc finger protein, putative Ixodes scapularis [XP_002408238.1] & $1^{\mathrm{e}-06}$ \\
\hline GBAI01000010 & BP6 & KSR 2 misexpression suppressor Amblyomma variegatum [DAA34564.1] & $7^{e-42}$ \\
\hline GBAK01000152 & BP13-14 & & $3^{e-42}$ \\
\hline GBAL01000052 & BP15-16 & & $3^{e-42}$ \\
\hline GBAK01000081 & BP13-14 & Misexpression suppressor of KSR, putative, mRNA Ixodes scapularis [XM_002411057.1] & $6^{\mathrm{e}-11}$ \\
\hline GBAK01000363 & BP13-14 & BRI1-KD interacting protein, putative Ixodes scapularis [XP_002434447.1] & $2^{\mathrm{e}-07}$ \\
\hline GBAL01000026 & BP15-16 & histone H2 Dermacentor variabilis [ACF35543.1] & $2^{\mathrm{e}-66}$ \\
\hline GBAL01000127 & BP15-16 & DEK domain-containing protein, putative Ixodes scapularis [XP_002400977.1] & $3^{\mathrm{e}-23}$ \\
\hline GBAK01000039 & BP13-14 & small nuclear ribonucleoprotein sm D2, putative Ixodes scapularis [XP_002411748.1] & $2^{\mathrm{e}-62}$ \\
\hline GBAL01000037 & BP15-16 & & $9^{e-63}$ \\
\hline GBAK01000113 & BP13-14 & snrnp sm protein, putative Ixodes scapularis [XP_002410602.1] & $7^{\mathrm{e}-05}$ \\
\hline GBAL01000243 & BP15-16 & $\begin{array}{l}\text { translation initiation factor } 3 \text { and TGF-beta interacting protein, putative } \\
\text { Ixodes scapularis [XP_002400973.1] }\end{array}$ & $1^{\mathrm{e}-54}$ \\
\hline GBAI01000025 & BP6 & translation initiation factor elF3, p35 subunit, putative Ixodes scapularis [XP_002412399.1] & $1^{\mathrm{e}-57}$ \\
\hline GBAL01000007 & BP15-16 & translation initiation factor 4 F cap-binding subunit Amblyomma variegatum [DAA34255.1] & $3^{\mathrm{e}-05}$ \\
\hline GBAL01000135 & BP15-16 & translation factor Amblyomma variegatum [DAA34728.1] & $4^{\mathrm{e}-22}$ \\
\hline GBAJ01000048 & BP10 & elF2B-gamma protein, putative Ixodes scapularis [XP_002414374.1] & $4^{e-39}$ \\
\hline \multirow[t]{2}{*}{ GBAK01000330 } & BP13-14 & translation initiation factor 4 F, helicase subunit, putative Ixodes scapularis [XP_002407236.1] & $1^{\mathrm{e}-81}$ \\
\hline & & DEAD box ATP-dependent RNA helicase, putative Ixodes scapularis [XP_002414033.1] & $2^{\mathrm{e}-69}$ \\
\hline \multirow[t]{2}{*}{ GBAL01000220 } & BP15-16 & ribosomal DEAD box protein, putative Ixodes scapularis [XP_002414143.1] & $3^{e^{-126}}$ \\
\hline & & DEAD box ATP-dependent RNA helicase, putative Ixodes scapularis [XP_002414033.1] & $8^{\mathrm{e}-62}$ \\
\hline GBAJ01000025 & BP10 & ATP-dependent RNA helicase pitchoune, putative Ixodes scapularis [XP_002401339.1] & $5^{e^{-128}}$ \\
\hline
\end{tabular}




\begin{tabular}{|c|c|c|c|}
\hline GBAK01000055 & BP13-14 & translation elongation factor EF-1 alpha/Tu, putative Ixodes scapularis [XP_002411147.1] & $5^{e^{-45}}$ \\
\hline GBAK01000396 & BP13-14 & elongation factor 1 gamma, putative Ixodes scapularis [XP_002410199.1] & $5^{e-12}$ \\
\hline GBAK01000102 & BP13-14 & isolate RAHD_87 Ruka SINE elements Rhipicephalus appendiculatus [EU018131.1] & $3^{e-16}$ \\
\hline GBAI01000020 & BP6 & transcription initiation factor IIA gamma chain, putative Ixodes scapularis [XP_002410024.1] & $1^{e-69}$ \\
\hline GBAK01000153 & BP13-14 & transcription initiation factor IID subunit Argas monolakensis [ABI52792.1] & $5^{e-27}$ \\
\hline GBAK01000297 & BP13-14 & & $1^{e-18}$ \\
\hline GBAL01000213 & BP15-16 & transcription factor E2F7, putative Ixodes scapularis [XP_002401356.1] & $6^{\mathrm{e}-06}$ \\
\hline GBAL01000259 & BP15-16 & transcription initiation factor TFII-D, subunit TAF10, putative Ixodes scapularis [XP_002409390.1] & $7^{\mathrm{e}-09}$ \\
\hline \multirow[t]{2}{*}{ GBAK01000321 } & BP13-14 & transcription factor containing NAC and TS-N domains, putative Ixodes scapularis [XP_002413138.1] & $1^{-17}$ \\
\hline & & transcription factor Amblyomma variegatum [DAA34590.1] & $4^{\mathrm{e}-12}$ \\
\hline GBAK01000162 & BP13-14 & methyl-CpG binding transcription regulator, putative Ixodes scapularis [XP_002407962.1] & $3^{e-12}$ \\
\hline GBAK01000056 & BP13-14 & cleavage/polyadenylation factor la subunit Clp1p, putative Ixodes scapularis [XP_002406587.1] & $3^{e-94}$ \\
\hline GBAK01000239 & BP13-14 & z-protein, putative Ixodes scapularis [XP_002401042.1] & $6^{\mathrm{e}-20}$ \\
\hline GBAK01000270 & BP13-14 & & $5^{e-20}$ \\
\hline GBAK01000212 & BP13-14 & coiled-coil domain-containing protein, putative Ixodes scapularis [XP_002402814.1] & $1^{e-32}$ \\
\hline GBAL01000077 & BP15-16 & & $9^{e-33}$ \\
\hline GBAL01000049 & BP15-16 & activating signal cointegrator 1 complex subunit, putative Ixodes scapularis [XP_002401442.1] & $8^{\mathrm{e}-43}$ \\
\hline GBAL01000076 & BP15-16 & & $2^{e^{-16}}$ \\
\hline GBAK01000231 & BP13-14 & cytochrome C, putative Ixodes scapularis [XP_002411082.1] & $2^{e-54}$ \\
\hline GBAJ01000096 & BP10 & cytochrome C Dermacentor variabilis [AAY86487.1] & $2^{e-62}$ \\
\hline \multirow[t]{4}{*}{ GBAJ01000064 } & BP10 & histamine release factor mRNA, complete cds Boophilus microplus [DQ009479.1] & $2^{e-62}$ \\
\hline & & histamine release factor mRNA, complete cds Amblyomma americanum [DQ009481.1] & $1^{\mathrm{e}-09}$ \\
\hline & & IgE-dependent histamine release factor mRNA, complete cds Dermacentor variabilis [AF467699.1] & $2^{\mathrm{e}-09}$ \\
\hline & & histamine release factor mRNA, complete cds Dermacentor andersoni [DQ009480.1] & $2^{\mathrm{e}-07}$ \\
\hline \multirow[t]{4}{*}{ GBAK01000197 } & BP13-14 & histamine release factor mRNA, complete cds Boophilus microplus [DQ009479.1] & $2^{\mathrm{e}-43}$ \\
\hline & & histamine release factor mRNA, complete cds Amblyomma americanum [DQ009481.1] & $3^{e-19}$ \\
\hline & & IgE-dependent histamine release factor mRNA, complete cds Dermacentor variabilis [AF467699.1] & $5^{e-23}$ \\
\hline & & histamine release factor mRNA, complete cds Dermacentor andersoni [DQ009480.1] & $1^{e-23}$ \\
\hline \multirow[t]{3}{*}{ GBAK01000077 } & BP13-14 & amercin Amblyomma americanum [ABI74752.1] & $1^{e-36}$ \\
\hline & & persulcatusin Ixodes persulcatus [BAH09304.1] & $4^{e-21}$ \\
\hline & & defensin 2 Haemaphysalis longicornis [ABW08118.1] & $1^{\mathrm{e}-20}$ \\
\hline GBAK01000137 & BP13-14 & putative beta thymosin Dermacentor variabilis [AAO92284.1] & $8^{e-36}$ \\
\hline GBAK01000092 & BP13-14 & gephyrin, putative Ixodes scapularis [XP_002404228.1] & $1^{e-67}$ \\
\hline GBAK01000219 & BP13-14 & $\begin{array}{l}\text { SNAP-25 (synaptosome-associated protein) component of SNARE complex, putative } \\
\text { Ixodes scapularis [XP_002404177.1] }\end{array}$ & $9^{e-46}$ \\
\hline GBAL01000092 & BP15-16 & vAMP-7, putative Ixodes scapularis [XP_002400270.1] & $7^{\mathrm{e}-50}$ \\
\hline GBAJ01000033 & BP10 & metaxin, putative Ixodes scapularis [XP_002404066.1] & $2^{e^{-131}}$ \\
\hline GBAK01000335 & BP13-14 & chaperonin complex component, TCP-1 eta subunit, putative Ixodes scapularis [XP_002415178.1] & $3^{\mathrm{e}-07}$ \\
\hline GBAK01000037 & BP13-14 & fidipidine, putative Ixodes scapularis [XP_002416086.1] & $1^{\mathrm{e}-06}$ \\
\hline GBAJ01000072 & BP10 & tetraspanin-like protein Dermacentor variabilis [AAL75584.1] & $1^{\mathrm{e}-87}$ \\
\hline GBAI01000038 & BP6 & saposin, putative Ixodes scapularis [XP_002412058.1] & $6^{\mathrm{e}-54}$ \\
\hline GBAL01000086 & BP15-16 & UBX domain-containing protein, putative Ixodes scapularis [XP_002413353.1] & 0.004 \\
\hline GBAK01000033 & BP13-14 & UBX domain-containing protein, putative Ixodes scapularis [XP_002403277.1] & $2^{\mathrm{e}-09}$ \\
\hline GBAK01000302 & BP13-14 & MYC-induced nuclear antigen, putative Ixodes scapularis [XP_002434908.1] & $1^{\mathrm{e}-11}$ \\
\hline GBAL01000246 & BP15-16 & $\begin{array}{l}\text { mitotic spindle assembly checkpoint protein MAD2A, putative } \\
\text { Ixodes scapularis [XP_002401838.1] }\end{array}$ & $1^{\mathrm{e}-40}$ \\
\hline
\end{tabular}


Table 8 Putative immunogenic proteins of miscellaneous function in Amblyomma americanum tick saliva (Continued)

\begin{tabular}{|c|c|c|c|}
\hline \multirow[t]{2}{*}{ GBAK01000377 } & BP13-14 & tumor rejection antigen (gp96), putative Ixodes scapularis [XP_002413149.1] & $8^{e^{-61}}$ \\
\hline & & Hsp90 protein, putative Ixodes scapularis [XP_002414808.1] & $3^{e-18}$ \\
\hline \multirow[t]{2}{*}{ GBAJ01000015 } & BP10 & heat shock 70 kDa protein 5 Haemaphysalis longicornis [ACA84007.1] & $5^{e^{-13}}$ \\
\hline & & heat shock protein, putative Ixodes scapularis [XP_002433656.1] & $4^{e^{-10}}$ \\
\hline \multirow[t]{2}{*}{ GBAL01000001 } & BP15-16 & heat shock $70 \mathrm{kDa}$ protein 5 Haemaphysalis longicornis [ACA84007.1] & $2^{e^{-50}}$ \\
\hline & & heat shock protein, putative Ixodes scapularis [XP_002433656.1] & $8^{\mathrm{e}-41}$ \\
\hline
\end{tabular}

for microbial organisms such as Borrelia burgdorferi, which do not require iron for growth [153], most microbial organisms need iron and/or heme to proliferate $[154,155]$. As an anti-microbial defense, mammalian hosts utilize ferritin to sequester iron and deny microbial organisms' access to it [156]. From this perspective, it is logical to speculate that presence of ferritin and HeLp in tick saliva is advantageous to microbial organisms in that secreted ferritin and HeLp will deliver iron and heme into the feeding site to the advantage of the transmitted tick borne disease agent. It interesting to note that ferritin was up regulated in $D$. variabilis ticks that were infected with Rickettsia montana [157].

Data in this study also advance our knowledge on the biology of tick ferritins. Two ferritin cDNAs have been described in ticks, ferritin- 1 which is deemed intracellular because it does not have a signal peptide, and ferritin-2, deemed secreted because it has a signal peptide $[142,149]$. It is notable that both of the two-ferritin sequences (GBAI01000078 and GBAJ01000019) in this study showed high amino acid identity to ferritin 1 and not ferritin 2 (not shown). The partial ferritin sequence fragment in this study, GBAI01000078 is $100 \%$ identical to $A$. americanum ferritin-1 (AAQ54708.1). In contrast, ferritin sequence GBAJ01000019 showed $~ 60 \%$ identity to tick ferritin-1 sequences and $98 \%$ amino acid identity to mammalian ferritin such as Canis lupus familiaris (NP_001003080.1) (not shown). Although further verification is needed data presented here indicates the presence of a third ferritin in ticks. It is also interesting to note that similar to dog ferritin-1 (NP_001003080.1), which is $98 \%$ identical to GBAJ01000019 does not have a signal peptide. These data may suggest that ferritin in A. americanum tick saliva are secreted in a noncanonical way. Consistent with findings in this study, tick ferritin and HeLp were detected in partially and fully engorged R. microplus proteome [75].

\section{Calcium binding proteins}

Table 5 lists sequences showing identity to four putative calcium binding proteins, including calmodulin (GBAI01 000083, GBAJ01000110, GBAK01000031, and GBAL010 00053), calponin (GBAI01000101), calreticulin (GBAJ01
000101 and GBAK01000025), and sarcoplasmic calcium binding protein (GBAL01000044). To complete feeding ticks must keep host blood in a fluid state at the tickfeeding site and in the midgut. Thus, given that calcium $\left(\mathrm{Ca}^{2+}\right)$ is the fourth co-factor of the blood clotting activation pathway [158], it is conceivable that ticks may secrete $\mathrm{Ca}^{2+}$ binding proteins into the tick-feeding site to bind and deplete $\mathrm{Ca}^{2+}$ and prevent activation of blood clotting. Apart from potential $\mathrm{Ca}^{2+}$ function, the four $A$. americanum tick saliva putative $\mathrm{Ca}^{2+}$ binding proteins in Table 5 could perform multiple other yet unknown functions in tick physiology. In relative terms, calreticultin (CRT) is the most studied tick calcium-binding protein; it is a validated cross-tick species conserved immunogenic tick saliva protein [159] that is currently used as a biomarker for human tick bites [160]. However beyond this, the role(s) of CRT at the tick-feeding site are unknown. Recombinant CRT of parasites such as Trypanosoma cruzi [161], H. contortus [162], Entamoeba histolytica [163], Trypanosoma carassii [164], blocks the complement activation cascade by binding $\mathrm{C} 1 \mathrm{q}$, the first factor of the cascade. Additionally $H$. contortus calreticulin was also shown to bind factor Xa [162], an important protease of the blood-clotting cascade [165]. In a related study (Kim and Mulenga, unpublished), showed that a yeast expressed recombinant $A$. americanum calreticulin bound $\mathrm{C} 1 \mathrm{q}$, but did not interfere with complement activation. From these data tick calreticulin may function differently when compared to other parasites. It is also interesting to note that both mammalian and parasite calreticulin were shown to enhance wound healing [166]. Whether or not, tick saliva calreticulin enhances wound healing has not been reported. If consistent with observations in other organisms, it would be counter-intuitive for tick calreticulin to enhance wound healing. Ticks begin the feeding process by creating a feeding lesion, and to continue feeding, ticks must block wound healing mechanisms for the feeding site to remain viable [167]. Similar to calreticulin, calmodulin is multifunctional protein that is primarily known for its roles in $\mathrm{Ca}^{2+}$ homeostasis in mammals [168]. Except for a single study that described a H. longicornis tick calmodulin-like protein [169], nothing is 
known about this protein in tick physiology. Similarly, there are no studies on the roles of calponin in tick physiology. In mammals, calponin performs multiple functions including regulation of actin, $\mathrm{Ca}^{2+}$, and ATPase [170-172]. Whether or not tick calponin is multifunctional remains to be determined. Similarly, there are no reported studies on the sarcoplasmic-calcium binding protein in ticks. This molecule has been characterized in multiple invertebrates [173-175], and is considered a key factor in human allergic reactions to shrimp [174,175]. It will be interesting to find out what these proteins do at the tick-feeding site.

\section{Fatty acid and histamine (lipocalin) binding proteins} Eight sequences (GBAI01000035, GBAK01000066, GBA K01000093, GBAK01000144, GBAK01000151, GBAL010 00122, GBAL01000248, and GBAL01000133) and one sequence (GBAJ01000056) are provisionally identified as putative histamine binding/lipocalin and fatty acid binding protein, respectively. Presence of lipid derivatives in tick saliva has been demonstrated, and been shown to play important roles in tick feeding success. Prostaglandins (PGs), derivatives of arachidonic acid, are important vasodilators, which contributes to the tick's ability to block vasoconstriction of host blood vessels as a host defense response to tissue injury during tick feeding [176]. Several studies demonstrated secretion of PGE2 [177-179] and prostacyclin (PGI) [32] in tick saliva. Tick saliva PGE2 was shown to interfere with function of macrophages [180] and dendritic [181] cells, which are important in host defense response [182,183]. Despite the demonstration that PGs are secreted into tick saliva, their mode of secretion has not been elucidated. There is a possibility that lipid-binding proteins found in this study serve as PG transporters. We would like to caution here that $A$. americanum hemolymph PGE2 was found not bound to any carrier protein [35] suggesting that it may not require a transporter protein. Thus there is a possibility that putative lipid binding proteins described here may perform other functions at the tick feeding site that may not be related to transporting lipids from the tick into the tick-feeding site.

Ticks have to overcome the host's inflammation response to complete feeding. Histamine is a potent proinflammatory molecule that is released by cellular mediators of inflammation such as mast cells and neutrophils [184]. Thus, it is logical that $A$. americanum tick saliva contains proteins like histamine-binding proteins/lipocalin to sequester histamine and stop the inflammation response. Histamine mediated cutaneous inflammation is one the host's defense reactions to tick feeding, as demonstrated by adverse effects on tick attachment, feeding efficiency, and reproductive success when histamine was elevated at the feeding site $[185,186]$.

\section{Nucleic acid binding proteins}

Table 5 lists three putative nucleotide binding proteins, GBAK01000068, GBAL01000186, and GBAJ01000103 that have been provisionally identified as respective GTPbinding, ATP-binding, and histidine triad known as purine-binding protein [187]. In addition, four sequences related to RNA- (GBAL01000055, GBAL01000072, and GBAL01000222) and DNA- (GBAK01000395) binding proteins were identified. Tick feeding involves disrupting host cells, which could lead to release of nucleic acids outside the cell. Extracellular nucleic acids are potent proinflammatory molecules. Thus listed putative nucleic acid binding proteins could be part of the ticks system to modulate host inflammation response to tick feeding activity. Here it is appropriate to mention that a number of sequences which showed identity to different transcriptional and translational factors, which are predicted to interact with nucleic acids (GBAI01000020, GBAI01000 025, GBAJ01000025, GBAJ01000048, GBAK01000039, GB AK01000055, GBAK01000102, GBAK01000113, GBAK01 000153, GBAK01000162, GBAK01000297, GBAK01000 321, GBAK01000330, GBAK01000337, GBAL01000007, GBAL01000037, GBAL01000127, GBAL01000135, GBA L01000213, GBAL01000220, GBAL01000243, and GBA L01000259), are listed in the Table 8.

\section{Immunoglobulin and other miscellaneous binding proteins}

Secretion of immunoglobulin G (IgG) in tick saliva was demonstrated [188], and thus the occurrence of IgG binding protein in A. americanum (GBAK01000082 and GBAK01000159) saliva is not surprising. While the possibility that this protein performing other functions at the tick-feeding site cannot be ruled out, it's most likely that the IgG binding protein in $A$. americanum tick saliva is used to eliminate host antibodies from the tick body during the feeding process, as previously supposed $[188,189]$.

Sequence GBAK01000246 showed similarity to insulinlike growth factor binding protein-related protein 6 (IGFBP-rP6). Mulenga and Khumthong [190] characterized two alternative IGFBP-rP6 sequences in A. americanum, short and long, and using dual RNAi silencing showed reduction in feeding efficiency in treated females. Although the function of IGFBP-rP6 in the tick feeding process is still unclear, our results here confirm the presence of this protein in tick saliva and that it's antigenic.

A lone sequence GBAL01000113 appeared similar to the chemokine binding protein evasin-1 from Rhipicephalus sanguineus, which displayed a high affinity for pro-inflammatory CCL3, CCL4, and CCL18 chemokines [191]. Pro-inflammatory chemokines are responsible for migration of lymphocytes to an injured site, which 
represents a key event in an immune response. Chemokines CCL3 and CCL4 both attract mononuclear cells, while CCL18 may be involved early in an immune response since it attracts naive CD45RA+T cells [192]. Chemokine sequestration by a chemokine binding proteins, secreted at the feeding site, helps ticks to evade host immune response.

Table 5 listed two sequences related to cyclophilin A (GBAK01000236 and GBAL01000024), a ubiquitous protein, which binds tightly to potent immunosuppressant cyclosporine A [193] and shows peptidyl-prolyl cistrans isomerase activity [194]. The immunosuppressive action is exerted through complex between cyclophiline $\mathrm{A}$, cyclosporine $\mathrm{A}$, and protein phosphatase known as calcineurin [195]. Phosphatase activity of calcineurin plays a role in activation of T cells [196]. Formation of cyclophiline A and cyclosporine A complex blocks calcineurin phosphatase activity, and subsequently inhibits T cell activation [197]. In addition, recently intracellular cyclophilin A was shown to be an important $\mathrm{Ca}^{2+}$ modulator in platelets [198]. Thus, we can speculate that cyclophilin A from tick saliva could be involved in both, evading host immune response and affecting primary hemostasis. It also seems that cyclophilin A plays a role in tick-pathogen interactions. Maeda et al. [199] suggested that cyclophilin A has regulatory role in the growth of Babesia parasites in H. longicornis ticks.

\section{Anti-oxidant and other enzymes}

Approximately $17 \%(81 / 464)$ of provisionally identified A. americanum immunogenic tick saliva protein sequences in this study are associated with anti-oxidant, energy metabolism, and other miscellaneous functions enzymes (Table 6). It is interesting to note that some of the housekeeping enzymes identified in this study were also found in $R$. sanguineus [200] and $R$. microplus [75] tick saliva proteomes ruling out the possibility that observations here could be a result of false antibody binding. In related studies, housekeeping proteins described here, were predicted to be secreted in saliva of $A$. americanum [201], I. scapularis [202], Dermacentor andersoni [203], and A. maculatum [108]. Except for putative antioxidants and a few others, the role(s) of the majority of listed enzymes in tick-host interactions are unclear. It is notable, but not surprising that $\sim 50 \%$ of $A$. americanum tick saliva enzymes in Table 6 including glutathione-S transferase (GST), protein disulfide isomerase, alkyl hydroperoxide reductase, cytochrome c oxidase, oxidoreductase, gamma-glutamyltransferase, NADH dehydrogenase, thioredoxin reductase, and peroxidase, which are putatively associated with an anti-oxidant functions [204-208]. Injury as occurs at the tick-feeding site induces oxidative stress leading to production of reactive oxygen and nitrogen species (ROS and RNS) as part of the wound healing mechanism [209] and anti-microbial defenses [210]. Several lines of research have shown that many parasites including ticks [211,212], helminths [213], Plasmodium spp. [214], Trypanosoma spp. [215], are susceptible to ROS and/or RNS, as revealed by high expression of antioxidant enzymes in these parasites or survival of these parasites when anti-oxidant systems of their hosts are impaired [216-218]. Thus it is fitting that A. americanum tick saliva will contain such a high number of putative antioxidants. Given the susceptibility of microbial organisms to oxidative stress products, anti-oxidants in tick saliva could be beneficial for transmission of tick borne diseases. It is also interesting to note that given that the tissue destroying effects of oxidative stress products are nonselective, there is a possibility that tick saliva anti-oxidants are protective to host tissue. Tick GST has been studied as a target anti-tick vaccine candidate and seems to confer protection in $R$. microplus and H. longicornis [219]. Here it is appropriate to mention that three sequences listed in Table 8 were provisionally identified as selenoproteins $\mathrm{K}$ (GBAK01000145 and GBAK01000160) and M (GBAI01 000072). Recently, both of them were associated with regulation of cytosolic $\mathrm{Ca}^{2+}$ flux, as well as with protective role against oxidative damages [220,221]. Presence of selenoproteins in saliva increases the power of ticks' anti-oxidative mechanism. Another notable interesting enzyme is D-dopachrome tautomerase, the functional homolog of macrophage migration inhibitory factor [222], which could be involved in mediating host defense mechanism.

\section{Ribosomal, heat shock proteins, histamine release factor, and other proteins of miscellaneous functions}

Table 7 lists ribosomal proteins in A. americanum tick saliva. Although the high number of ribosomal proteins may be surprising, the presence of these proteins in tick saliva is relatable to events that facilitate tick-host interactions. Ribosomal proteins function is predominantly intracellular, but several studies have described extracellular functions of ribosomal proteins in mammals exerting anti-inflammatory activity [223-225]. One of the most studied, ribosomal protein S19 was recently shown to bind the pro-inflammatory cytokines [224]. Whether or not A. americanum putative S19 protein (GBAI01000085, GBAJ01000004, and GBAK01000158) will functionally bind pro-inflammatory cytokines remains to be investigated. It is conceivable that ribosomal-like proteins in tick saliva could be part of the tick's system to evade the host's inflammation defense response to tick feeding. Indirect evidence suggests that other parasites use ribosomal proteins to evade host defenses. A Leishmania S3a ribosomal protein was associated with balancing between Th1 and Th2 immune responses [226], while ribosomal protein 
L12 was crucial in gonococcal invasion of human reproductive cells [227].

Like ribosomal proteins, extracellular heat shock proteins (HSP) are potent anti-inflammatory molecules [228] and thus, presence of HSP70 and gp96-like proteins in A. americanum tick saliva (Table 8) could mean that the tick uses these proteins to evade the host's inflammation defense against tick feeding. The observation of the tick histamine release factor (tHRF) in A. americanum confirms previously published studies that demonstrated presence of functional tHRF in $D$. variabilis tick saliva [62,63]. What is interesting, however is that the occurrence of this protein in tick saliva is counterintuitive in that if functional at the tick-feeding site, its actions will promote inflammation, which is what the tick is trying to defeat. It is notable that tHRF was linked to interactions between ticks and pathogens in that the encoding mRNA was up regulated in $R$. montanainfected D. variabilis [157] and associated with Borrelia transmission by I. scapularis ticks [229].

Among other notable proteins of miscellaneous function in $A$. americanum tick saliva (Table 8) include zinc finger-like proteins (GBAJ01000053, GBAK01000084, GBAL01000011, and GBAL01000027). Members of the zinc finger protein family are structurally diverse and are involved with many functions including, replication and repair, transcription and translation, metabolism and signaling, cell proliferation and apoptosis [230]. Typical zinc finger protein ligands include nucleic acids, proteins, and important small molecules [230].

Other interesting sequences include contigs GBAK01 000239 and GBAK01000270 that were provisionally identified as z-proteins (Table 8), known as cofactors in coagulation factor Xa degradation by z-protein dependent protease inhibitor [231]. In murine model, z-protein and z-protein dependent protease inhibitor deficiency enhances thrombosis [232], which indicates their important role in preventing blood coagulation in homeostasis. Secretion of tick z-protein at the feeding site probably helps in local inhibition of the host coagulation cascade.

A lone sequence GBAK01000077 showed similarity to defensin proteins, an antimicrobial agent of innate immunity [233]. A defensins were described in several hard tick species. Persulcatusin, from Ixodes persulcatus, found to be predominantly expressed in the midgut of adult females, and as recombinant peptide displayed antibacterial activity toward Gram-positive bacteria [234]. Defensin gene in A. americanum was found to be expressed in both, midgut and salivary glands [235]. Data here is the first demonstration of defensin proteins in tick saliva. In addition to evading host defenses to tick feeding, and ensuring that blood does not clot, the tick must prevent bacterial or microbial colonization of the feeding site. Thus, it's conceivable that defensin in tick saliva could be used to keep infections of the feeding site.

Other proteins found in A. americanum saliva were related to the protein translation machinery and structural related, myosin-like and paramyosin proteins. The roles of these proteins at the tick-feeding site remain to be explored. It is interesting to note that $R$. microplus paramyosin was reactive with tick immune sera [236,237] suggesting that it was part of the immunogenic tick saliva protein complex that conferred anti-tick resistance in repeatedly infested animals.

At a glance, it is surprising that we identified a large number of intracellular proteins in tick saliva. We belive this could be due to the mode of salivary secretion. There are described mechanisms of exocytosis of proteins from salivary gland cells into the saliva [238,239], but massive appearance of originally intracellular proteins in tick saliva suggests actuality of previously proposed holocrine or apocrine modes of salivary secretion [240].

\section{Conclusion}

Multiple tick salivary gland transcriptomes have predicted secreted tick salivary proteins [108,114,241-244], while two recent studies provided insight into the complexity of tick saliva proteomes $[75,200]$. This study contributes to the emerging and growing knowledge on the complexity of the immunogenic $A$. americanum tick saliva proteome. Data here provides an interesting foundation on the range of candidate proteins to be screened in the quest to discover anti-tick target vaccine antigens. One of the key observations in this study is that housekeeping-like proteins were immunogenic, and thus must be given a new look in our search for anti-tick vaccine antigens. Given that housekeeping proteins tend to be highly conserved across taxa, one may assume that they were more likely not to provoke an immune reaction. Could it be that, although primary structures were highly conserved, there are important secondary structure departures that prevented the host from recognizing these proteins as self? The biopanning approach used here has limitations, and thus identification of some proteins here could be result of the cross-reactivity of antibodies used here with none-tick saliva proteins. We are confident that this is not the case in that previously confirmed tick saliva proteins, including tHRF [62], AV422 [70], paramyosin [236], defensin [235], selenoproteins [108], calreticulin [245], and histamine binding/lipocalins [54] were found in this study. This study though descriptive provides a foundation for the design of antitick target vaccine antigens.

\section{Availability of supporting data}

All the supporting data are included as an additional file. 


\section{Additional file}

\section{Additional file 1: List of sequences encoding hypothetical immunogenic 24-48 h fed Amblyomma americanum tick saliva proteins which do not match tick sequences present in GenBank.}

\section{Competing interests}

The authors declare that they have no competing interests.

\section{Authors' contributions}

AM designed and coordinated the experiment, participated in data analysis and interpretation, and manuscript drafting and editing. ŽMR carried out parent libraries construction, biopanning protocol, and preparation of samples for the next generation sequencing, participated in data analysis and manuscript drafting and editing. TKK prepared templates used for libraries construction and participated in manuscript editing. LMP performed bioinformatic analysis of the next generation sequencing data and participated in data analysis and manuscript editing. S-HS participated in bioinformatic analysis. LL participated in data analysis and manuscript editing. All authors read and approved the final manuscript.

\section{Acknowledgements}

This work was supported by the National Institute of Allergy and Infectious Diseases/National Institutes of Health (NIAID/NIH) grants (Al081093 and Al093858) to AM.

\section{Author details}

'Department of Entomology, AgriLife Research, Texas A \& M University, 2475 TAMU, College Station TX77843, USA. ${ }^{2}$ Department of Computer Sciences and Engineering, Texas A \& M University, College Station TX77843, USA. ${ }^{3}$ Department of Biochemistry \& Biophysics, Texas A \& M University, College Station TX77843, USA.

Received: 1 April 2014 Accepted: 12 June 2014

Published: 24 June 2014

\section{References}

1. Sonenshine DE: The Biology of Ticks Vol. 2. Oxford University Press, Incorporated; 1993.

2. Jongejan F, Uilenberg G: The global importance of ticks. Parasitology 2004, 129:S3-S14.

3. Minjauw B, McLeod A: Tick-borne diseases and poverty: the impact of ticks and tick-borne diseases on the livelihoods of small-scale and marginal livestock owners in India and eastern and southern Africa. In Research report, DFID Animal Health Programme, Centre for Tropical Veterinary Medicine. UK: University of Edinburgh; 2003.

4. Grisi L, Massard C, Moya Borja G, Pereira J: Impacto econômico das principais ectoparasitoses em bovinos no Brasil. A Hora Veterinária 2002, 21:8-10.

5. Childs JE, Paddock CD: The ascendancy of Amblyomma americanum as a vector of pathogens affecting humans in the United States. Annu Rev Entomol 2003, 48:307-337.

6. Keirans JE, Lacombe EH: First records of Amblyomma americanum, Ixodes (Ixodes) dentatus, and Ixodes (Ceratixodes) uriae (Acari: Ixodidae) from Maine. J Parasitol 1998, 84:629-631.

7. Mixson TR, Lydy SL, Dasch GA, Real LA: Inferring the population structure and demographic history of the tick, Amblyomma americanum Linnaeus. J Vector Ecol 2006, 31:181-192.

8. Felz MW, Durden LA, Oliver JH Jr: Ticks parasitizing humans in Georgia and South Carolina. J Parasitol 1996, 82:505-508.

9. Hopla CE: Experimental studies on tick transmission of tularemia organisms. Am J Hyg 1953, 58:101-118.

10. Taylor JP, Istre GR, McChesney TC, Satalowich FT, Parker RL, McFarland LM: Epidemiologic characteristics of human tularemia in the southwestcentral states, 1981-1987. Am J Epidemiol 1991, 133:1032-1038.

11. Anderson BE, Sims KG, Olson JG, Childs JE, Piesman JF, Happ CM, Maupin $\mathrm{GO}$, Johnson BJ: Amblyomma americanum: a potential vector of human ehrlichiosis. Am J Trop Med Hyg 1993, 49:239-244.
12. Murphy GL, Ewing SA, Whitworth LC, Fox JC, Kocan AA: A molecular and serologic survey of Ehrlichia canis, E. chaffeensis, and E. ewingii in dogs and ticks from Oklahoma. Vet Parasitol 1998, 79:325-339.

13. Buller RS, Arens M, Hmiel SP, Paddock CD, Sumner JW, Rikihisa Y, Unver A, Gaudreault-Keener M, Manian FA, Liddell AM, Schmulewitz N, Storch GA: Ehrlichia ewingii, a newly recognized agent of Human Ehrlichiosis. N Engl J Med 1999, 341:148-155.

14. Wolf L, McPherson T, Harrison B, Engber B, Anderson A, Whitt P: Prevalence of Ehrlichia ewingii in Amblyomma americanum in North Carolina. J Clin Microbiol 2000, 38:2795-2795.

15. James AM, Liveris D, Wormser GP, Schwartz I, Montecalvo MA, Johnson BJ: Borrelia lonestari infection after a bite by an Amblyomma americanum tick. J Infect Dis 2001, 183:1810-1814.

16. Armstrong PM, Brunet LR, Spielman A, Telford SR 3rd: Risk of Lyme disease: perceptions of residents of a Lone Star tick-infested community. Bull World Health Organ 2001, 79:916-925.

17. Reeves W, Loftis A, Nicholson W, Czarkowski A: The first report of human illness associated with the Panola Mountain Ehrlichia species: a case report. J Med Case Reports 2008, 2:139.

18. Yabsley MJ, Loftis AD, Little SE: Natural and experimental infection of white-tailed deer (Odocoileus virginianus) from the United States with an Ehrlichia sp. closely related to Ehrlichia ruminantium. J Wildl Dis 2008, 44:381-387.

19. Savage HM, Godsey MS Jr, Lambert A, Panella NA, Burkhalter KL, Harmon JR, Lash RR, Ashley DC, Nicholson WL: First detection of heartland virus (Bunyaviridae: Phlebovirus) from field collected arthropods. Am J Trop Med Hyg 2013, 89:445-452.

20. Apperson CS, Engber B, Nicholson WL, Mead DG, Engel J, Yabsley MJ, Dail K Johnson J, Watson DW: Tick-borne diseases in North Carolina: is "Rickettsia amblyommii" a possible cause of rickettsiosis reported as Rocky Mountain spotted fever? Vector Borne Zoonotic Dis 2008, 8:597-606.

21. Laird JS, Kocan AA, Kocan KM, Presley SM, Hair JA: Susceptibility of Amblyomma americanum natural and experimental infections with Theileria cervi. J Wild Dis 1988, 24:679-683.

22. Little SE, O'Connor TP, Hempstead J, Saucier J, Reichard MV, Meinkoth K Meinkoth JH, Andrews B, Ullom S, Ewing SA, Chandrashekar R: Ehrlichia ewingii infection and exposure rates in dogs from the southcentral United States. Vet Parasitol 2010, 172:355-360.

23. Yabsley MJ, Quick TC, Little SE: Theileriosis in a white-tailed deer (Odocoileus virginianus) fawn. J Wildl Dis 2005, 41:806-809.

24. Ghosh S, Azhahianambi P, Yadav M: Upcoming and future strategies of tick control: a review. J Vector Borne Dis 2007, 44:79.

25. Willadsen P: Novel vaccines for ectoparasites. Vet Parasitol 1997, 71:209-222.

26. Pruett JH: Immunological control of arthropod ectoparasites-a review. Int J Parasitol 1999, 29:25-32

27. Mulenga A, Sugimoto C, Sako Y, Ohashi K, Musoke A, Shubash M, Onuma M: Molecular characterization of a Haemaphysalis longicornis tick salivary gland-associated 29-kilodalton protein and its effect as a vaccine against tick infestation in rabbits. Infect Immun 1999, 67:1652-1658.

28. de la Fuente J, Kocan KM: Advances in the identification and characterization of protective antigens for recombinant vaccines against tick infestations. Expert Rev Vaccines 2003, 2:583-593.

29. Canales M, Almazán C, Naranjo V, Jongejan F, De la Fuente J: Vaccination with recombinant Boophilus annulatus Bm86 ortholog protein, Ba86, protects cattle against $B$. annulatus and B. microplus infestations. BMC Biotechnol 2009, 9:29.

30. Willadsen P: Anti-tick vaccines. Parasitology 2004, 129(Suppl):S367-S387.

31. Ribeiro JC: Ixodes dammini: Salivary anti-complement activity. Exp Parasitol 1987, 64:347-353.

32. Ribeiro J, Makoul G, Robinson D: Ixodes dammini: evidence for salivary prostacyclin secretion. J Parasitol 1988, 74:1068-1069.

33. Ribeiro JMC, Makoul G, Levine J, Robinson D, Spielman A: Antihemostatic, anti-inflammatory and immunosuppressive properties of the saliva of the tick, Ixodes dammini. J Exp Med 1985, 161:332-344.

34. Inokuma $\mathrm{H}, \mathrm{Kemp} \mathrm{DH}$, Willadsen $\mathrm{P}$ : Comparison of prostaglandin E2 (PGE2) in salivary gland of Boophilus microplus, Haemaphysalis longicornis and Ixodes holocyclus, and quantification of PGE2 in saliva, hemolymph, ovary and gut of B. microplus. J Vet Med Sci 1994, 56:1217-1218.

35. Aljamali M, Bowman AS, Dillwith JW, Tucker JS, Yates GW, Essenberg RC, Sauer JR: Identity and synthesis of prostaglandins in the lone star tick 
Amblyomma americanum (L.), as assessed by radio-immunoassay and gas chromatography/mass spectrometry. Insect Biochem Mol Biol 2002, 32:331-341.

36. Karczewski J, Endris R, Connolly TM: Disagregin is a fibrinogen receptor antagonist lacking the Arg-Gly-Asp sequence from the tick, Ornithodoros moubata. J Biol Chem 1994, 269:6702-6708.

37. Wang X, Coons LB, Taylor DB, Stevens SE, Gartner TK: Variabilin, a novel RGD-containing antagonist of glycoprotein Ilb-Illa and platelet aggregation inhibitor from the hard tick Dermacentor variabilis. J Biol Chem 1996, 271:17785-17790.

38. Mans BJ, Louw Al, Neitz AW: Amino acid sequence and structure modeling of savignin, a thrombin inhibitor from the tick, Ornithodoros savignyi. Insect Biochem Mol Biol 2002, 32:821-828.

39. Limo MK, Voigt WP, Tumbo-Oeri AG, Njogu RM, ole MoiYoi OK: Purification and characterization of an anticoagulant from the salivary glands of the ixodid tick Rhipicephalus appendiculatus. Exp Parasitol 1991, 72:418-429.

40. Joubert AM, Crause JC, Gaspar ARMD, Clarke FC, Spickett AM, Neitz AWH: Isolation and characterization of an anticoagulant present in the salivary glands of the bont-legged tick, Hyalomma truncatum. Exp Appl Acarol 1995, 19:79-92.

41. van de Locht A, Stubbs MT, Bode W, Friedrich T, Bollschweiler C, Hoffken W, Huber R: The ornithodorin-thrombin crystal structure, a key to the TAP enigma? EMBO J 1996, 15:6011-6017.

42. Gaspar ARMD, Joubert AM, Crause JC, Neitz AWH: Isolation and characterization of an anticoagulant from the salivary glands of the tick, Ornithodoros savignyi (Acari: Argasidae). Exp Appl Acarol 1996, 20:583-598.

43. Joubert AM, Louw Al, Joubert F, Neitz AW: Cloning, nucleotide sequence and expression of the gene encoding factor Xa inhibitor from the salivary glands of the tick, Ornithodoros savignyi. Exp Appl Acarol 1998, 22:603-619.

44. Nienaber J, Gaspar AR, Neitz AW: Savignin, a potent thrombin inhibitor isolated from the salivary glands of the tick Ornithodoros savignyi (Acari: Argasidae). Exp Parasitol 1999, 93:82-91.

45. Horn F, Coutinho dos Termignoni C, Santos P: Boophilus microplus anticoagulant protein: an antithrombin inhibitor isolated from the cattle tick saliva. Arch Biochem Biophys 2000, 384:68-73.

46. Ibrahim MA, Ghazy AH, Maharem TM, Khalil Ml: Factor Xa (FXa) inhibitor from the nymphs of the camel tick Hyalomma dromedarii. Comp Biochem Physiol B Biochem Mol Biol 2001, 130:501-512.

47. Narasimhan S, Koski RA, Beaulieu B, Anderson JF, Ramamoorthi N, Kantor F, Cappello M, Fikrig E: A novel family of anticoagulants from the saliva of Ixodes scapularis. Insect Mol Biol 2002, 11:641-650.

48. Francischetti IMB, Valenzuela JG, Andersen JF, Mather TN, Ribeiro JMC: Ixolaris, a novel recombinant tissue factor pathway inhibitor (TFPI) from the salivary gland of the tick, Ixodes scapularis: identification of factor $X$ and factor Xa as scaffolds for the inhibition of factor VIla/tissue factor complex. Blood 2002, 99:3602-3612.

49. Iwanaga S, Okada M, Isawa H, Morita A, Yuda M, Chinzei Y: Identification and characterization of novel salivary thrombin inhibitors from the ixodidae tick, Haemaphysalis longicornis. Eur J Biochem 2003, 270:1926-1934.

50. Liao M, Zhou J, Gong H, Boldbaatar D, Shirafuji R, Battur B, Nishikawa Y, Fujisaki K: Hemalin, a thrombin inhibitor isolated from a midgut CDNA library from the hard tick Haemaphysalis longicornis. J Insect Physio/ 2009, 55:165-174.

51. Narasimhan S, Perez O, Mootien S, DePonte K, Koski RA, Fikrig E, Ledizet M: Characterization of Ixophilin, a thrombin inhibitor from the gut of Ixodes scapularis. PLoS One 2013, 8:e68012.

52. Mulenga A, Kim T, Ibelli AMG: Amblyomma americanum tick saliva serine protease inhibitor 6 is a cross-class inhibitor of serine proteases and papain-like cysteine proteases that delays plasma clotting and inhibits platelet aggregation. Insect Mol Biol 2013, 22:306-319.

53. Paesen GC, Adams PL, Harlos K, Nuttall PA, Stuart DI: Tick histaminebinding proteins: isolation, cloning, and three-dimensional structure. Mol Cell 1999, 3:661-671.

54. Sangamnatdej S, Paesen GC, Slovak M, Nuttall PA: A high affinity serotonin- and histamine-binding lipocalin from tick saliva. Insect Mol Biol 2002, 11:79-86.

55. Valenzuela JG, Charlab R, Mather TN, Ribeiro JM: Purification, cloning, and expression of a novel salivary anticomplement protein from the tick, Ixodes scapularis. J Biol Chem 2000, 275:18717-18723.
56. Nunn MA, Sharma A, Paesen GC, Adamson S, Lissina O, Willis AC, Nuttall PA: Complement Inhibitor of C5 Activation from the Soft Tick Ornithodoros moubata. J Immunol 2005, 174:2084-2091

57. Lawrie $\mathrm{CH}$, Sim RB, Nuttall PA: Investigation of the mechanisms of anti-complement activity in Ixodes ricinus ticks. Mol Immunol 2005, 42:31-38.

58. Schroeder H, Daix V, Gillet L, Renauld J, Vanderplasschen A: The paralogous salivary anti-complement proteins IRAC I and IRAC II encoded by Ixodes ricinus ticks have broad and complementary inhibitory activities against the complement of different host species. Microb Infect 2007, 9:247-250.

59. Tyson K, Elkins C, Patterson H, Fikrig E, De Silva A: Biochemical and functional characterization of Salp20, an Ixodes scapularis tick salivary protein that inhibits the complement pathway. Insect Mol Biol 2007, 16:469-479.

60. Ribeiro JMC, Mather TN: Ixodes scapularis: salivary kininase activity is a metallo dipeptidyl carboxypeptidase. Exp Parasitol 1998, 89:213-221.

61. Bastiani M, Hillebrand S, Horn F, Kist TBL, Guimarães JA, Termignoni C: Cattle tick Boophilus microplus salivary gland contains a thiol-activated metalloendopeptidase displaying kininase activity. Insect Biochem Mol Biol 2002, 32:1439-1446.

62. Mulenga A, Macaluso KR, Simser JA, Azad AF: The American dog tick, Dermacentor variabilis, encodes a functional histamine release factor homolog. Insect Biochem Mol Biol 2003, 33:911-919.

63. Mulenga A, Azad AF: The molecular and biological analysis of ixodid ticks histamine release factors. Exp Appl Acarol 2005, 37:215-229.

64. Akdis CA, Blaser K: Histamine in the immune regulation of allergic inflammation. J Allergy Clin Immunol 2003, 112:15-22.

65. Trager W: Acquired immunity to ticks. J Parasitol 1939, 25:57-81.

66. Trager $\mathrm{W}$ : A note on the problem of acquired immunity to argasid ticks. J Parasitol 1940, 26:71-74.

67. Jaworski DC, Muller MT, Simmen FA, Needham GR: Amblyomma americanum: Identification of tick salivary gland antigens from unfed and early feeding females with comparisons to Ixodes dammini and Dermacentor variabilis. Exp Parasitol 1990, 70:217-226.

68. da Silva Vaz Jr I, Ozaki LS, Masuda A: Serum of Boophilus microplus infested cattle reacts with different tick tissues. Vet Parasitol 1994, 52(1-2):71-78.

69. Martin SJ: The Biochemistry of Viruses. Cambridge: Cambridge University Press; 1978.

70. Mulenga A, Kim TK, Ibelli AM: Deorphanization and target validation of cross-tick species conserved novel Amblyomma americanum tick saliva protein. Int J Parasitol 2013, 43:439-451.

71. Anderson J, Sonenshine D, Valenzuela J: Exploring the mialome of ticks: an annotated catalogue of midgut transcripts from the hard tick, Dermacentor variabilis (Acari: Ixodidae). BMC Genomics 2008, 9:552.

72. Ribeiro J, Anderson J, Manoukis N, Meng Z, Francischetti I: A further insight into the sialome of the tropical bont tick, Amblyomma variegatum. BMC Genomics 2011, 12:136.

73. Belley A, Keller K, Gottke M, Chadee K: Intestinal mucins in colonization and host defense against pathogens. Am J Trop Med Hyg 1999, 60 (Suppl):10-15.

74. Marin F, Luquet G, Marie B, Medakovic D: Molluscan shell proteins: primary structure, origin, and evolution. Curr Top Dev Biol 2007, 80:209-276.

75. Tirloni L, Reck J, Terra RMS, Martins JR, Mulenga A, Sherman NE, Fox JW, Yates JR III, Termignoni C, Pinto AFM, da Silva Vaz I Jr: Proteomic analysis of cattle tick Rhipicephalus (Boophilus) microplus saliva: a comparison between partially and fully engorged females. PLoS One 2014, In press doi:10.1371/journal.pone.0094831.

76. Shinomiya H, Hagi A, Fukuzumi M, Mizobuchi M, Hirata H, Utsumi S: Complete primary structure and phosphorylation site of the $65-\mathrm{kDa}$ macrophage protein phosphorylated by stimulation with bacterial lipopolysaccharide. J Immunol 1995, 154:3471-3478.

77. Fagotto F: Yolk degradation in tick eggs: I. Occurrence of a cathepsin L-like acid proteinase in yolk spheres. Arch Insect Biochem Physiol 1990, 14:217-235

78. Pohl PC, Sorgine MHF, Leal AT, Logullo C, Oliveira PL, da Silva Vaz Jr I, Masuda A: An extraovarian aspartic protease accumulated in tick oocytes with vitellin-degradation activity. Comp Biochem Physiol Part B Biochem Mol Biol 2008, 151:392-399.

79. Mendiola J, Alonso M, Marquetti MC, Finlay C: Boophilus microplus: multiple proteolytic activities in the midgut. Exp Parasitol 1996, 82:27-33. 
80. Franta Z, Frantova H, Konvickova J, Horn M, Sojka D, Mares M, Kopacek P. Dynamics of digestive proteolytic system during blood feeding of the hard tick Ixodes ricinus. Parasit Vectors 2010, 3:119.

81. Miyoshi T, Tsuji N, Islam MK, Kamio T, Fujisaki K: Cloning and molecular characterization of a cubilin-related serine proteinase from the hard tick Haemaphysalis longicornis. Insect Biochem Mol Biol 2004, 34:799-808.

82. Hatta T, Umemiya R, Liao M, Gong H, Harnnoi T, Tanaka M, Miyoshi T, Boldbaatar D, Battsetseg B, Zhou J: RNA interference of cytosolic leucine aminopeptidase reduces fecundity in the hard tick, Haemaphysalis longicornis. Parasitol Res 2007, 100:847-854.

83. Leal AT, Seixas A, Pohl PC, Ferreira CAS, Logullo C, Oliveira PL, Farias SE, Termignoni C, da Silva Vaz Jr I, Masuda A: Vaccination of bovines with recombinant Boophilus yolk pro-Cathepsin. Vet Immunol Immunopathol 2006, 114:341-345

84. Crooks SW, Stockley RA: Leukotriene B4. Int J Biochem Cell Biol 1998, 30:173-178.

85. Weller CL, Collington SJ, Brown JK, Miller HR, Al-Kashi A, Clark P, Jose PJ, Hartnell A, Williams TJ: Leukotriene B4, an activation product of mast cells, is a chemoattractant for their progenitors. J Exp Med 2005, 201:1961-1971.

86. Le Bel M, Brunet A, Gosselin J: Leukotriene B4, an endogenous stimulator of the innate immune response against pathogens. J Innate Immun 2014, 6:159-168.

87. Mancuso P, Lewis C, Serezani CH, Goel D, Peters-Golden M: Intrapulmonary administration of leukotriene B4 enhances pulmonary host defense against pneumococcal pneumonia. Infect Immun 2010, 78:2264-2271.

88. Sisson JH, Prescott SM, Mclntyre TM, Zimmerman GA: Production of platelet-activating factor by stimulated human polymorphonuclear leukocytes. Correlation of synthesis with release, functional events, and leukotriene B4 metabolism. J Immunol 1987, 138:3918-3926.

89. Murphy RC, Gijon MA: Biosynthesis and metabolism of leukotrienes Biochem J 2007, 405:379-395

90. Turk V, Stoka V, Vasiljeva O, Renko M, Sun T, Turk B, Turk D: Cysteine cathepsins: From structure, function and regulation to new frontiers. Biochim Biophys Acta 1824, 2012:68-88.

91. Roberts R: Lysosomal cysteine proteases: structure, function and inhibition of cathepsins. Drug News Perspect 2005, 18:605-614.

92. Brömme D, Wilson S: Role of cysteine cathepsins in extracellular proteolysis. In Extracellular matrix degradation. Berlin Heidelberg: Springer; 2011:23-51

93. Conus S, Simon H: Cathepsins and their involvement in immune responses. Swiss Med Wkly 2010, 140:w13042.

94. Serveau-Avesque C, Martino MF, Hervé-Grépinet V, Hazouard E, Gauthier F, Diot $E$, Lalmanach $G$ : Active cathepsins $B, H, K, L$ and $S$ in human inflammatory bronchoalveolar lavage fluids. Biol Cell 2006, 98:15-22.

95. Lavoipierre M: Feeding mechanism of blood-sucking arthropods. Nature 1965, 208:302-303.

96. Midwood KS, Williams LV, Schwarzbauer JE: Tissue repair and the dynamics of the extracellular matrix. Int J Biochem Cell Biol 2004, 36:1031-1037.

97. Martin P, Leibovich SJ: Inflammatory cells during wound repair: the good, the bad and the ugly. Trends Cell Biol 2005, 15:599-607.

98. Hu DD, Cui J, Wang L, Liu LN, Wei T, Wang ZQ: Immunoproteomic analysis of the excretory-secretory proteins from Spirometra mansoni Sparganum. Iran J Parasitol 2013, 8:408-416.

99. Shareef PA, Abidi S: Cysteine protease is a major component in the excretory/secretory products of Euclinostomum heterostomum (Digenea: Clinostomidae). Parasitol Res 2014, 113:65-71.

100. Smith AM, Dowd AJ, Heffernan M, Robertson CD, Dalton JP: Fasciola hepatica: A secreted cathepsin L-like proteinase cleaves host immunoglobulin. Int J Parasitol 1993, 23:977-983.

101. Doyle PS, Zhou YM, Engel JC, McKerrow JH: A cysteine protease inhibitor cures Chagas' disease in an immunodeficient-mouse model of infection. Antimicrob Agents Chemother 2007, 51:3932-3939.

102. Olson JE, Lee GK, Semenov A, Rosenthal PJ: Antimalarial effects in mice of orally administered peptidyl cysteine protease inhibitors. Bioorg Med Chem 1999, 7:633-638.

103. Tsuji N, Miyoshi T, Battsetseg B, Matsuo T, Xuan X, Fujisaki K: A cysteine protease is critical for Babesia spp. transmission in Haemaphysalis ticks. PLoS Pathog 2008, 4:e1000062.
104. Sexton KB, Witte MD, Blum G, Bogyo M: Design of cell-permeable, fluorescent activity-based probes for the lysosomal cysteine protease asparaginyl endopeptidase (AEP)/legumain. Bioorg Med Chem Lett 2007, 17:649-653.

105. Dalton JP, Clough KA, Jones MK, Brindley PJ: The cysteine proteinases of Schistosoma mansoni cercariae. Parasitology 1997, 114:105-112.

106. Abdul-Alim M, Tsuji N, Miyoshi T, Khyrul IM, Huang X, Motobu M, Fujisaki K: Characterization of asparaginyl endopeptidase, legumain induced by blood feeding in the ixodid tick Haemaphysalis longicornis. Insect Biochem Mol Biol 2007, 37:911-922.

107. Horn M, Nussbaumerova M, Sanda M, Kovarova Z, Srba J, Franta Z, Sojka D, Bogyo M, Caffrey CR, Kopacek P, Mares M: Hemoglobin digestion in blood-feeding ticks: mapping a multipeptidase pathway by functional proteomics. Chem Biol 2009, 16:1053-1063.

108. Karim S, Singh P, Ribeiro JMC: A deep insight into the sialotranscriptome of the Gulf Coast Tick. Amblyomma maculatum PLoS One 2011, 6:e28525.

109. Motobu M, Tsuji N, Miyoshi T, Huang X, Islam MK, Alim MA, Fujisaki K: Molecular characterization of a blood-induced serine carboxypeptidase from the ixodid tick Haemaphysalis longicornis. FEBS J 2007, 274:3299-3312.

110. Soblik H, Younis AE, Mitreva M, Renard BY, Kirchner M, Geisinger F, Steen H, Brattig NW: Life cycle stage-resolved proteomic analysis of the excretome/secretome from Strongyloides ratti-identification of stage-specific proteases. Mol Cell Proteomics 2011, 10:M111.010157.

111. Morassutti AL, Levert K, Pinto PM, da Silva AJ, Wilkins P, Graeff-Teixeira C: Characterization of Angiostrongylus cantonensis excretory-secretory proteins as potential diagnostic targets. Exp Parasitol 2012, 130:26-31.

112. Pshezhetsky AV, Hinek A: Serine carboxypeptidases in regulation of vasoconstriction and elastogenesis. Trends Cardiovasc Med 2009, 19:11-17.

113. Zhang R, Xu X, Chen T, Li L, Rao P: An assay for angiotensin-converting enzyme using capillary zone electrophoresis. Anal Biochem 2000, 280:286-290.

114. Valenzuela JG, Francischetti JM, Pham VM, Garfield MK, Mather TN, Ribeiro JM: Exploring the sialome of the tick Ixodes scapularis. J Exp Biol 2002, 205:2843-2864.

115. Harnnoi T, Sakaguchi T, Nishikawa Y, Xuan X, Fujisaki K: Molecular characterization and comparative study of 6 salivary gland metalloproteases from the hard tick, Haemaphysalis longicornis. Comp Biochem Physiol Part B Biochem Mol Biol 2007, 147:93-101.

116. Decrem Y, Beaufays J, Blasioli V, Lahaye K, Brossard M, Vanhamme L, Godfroid E: A family of putative metalloproteases in the salivary glands of the tick Ixodes ricinus. FEBS J 2008, 275:1485-1499.

117. Barnard A, Nijhof AM, Gaspar AR, Neitz AW, Jongejan F, Maritz-Olivier C: Expression profiling, gene silencing and transcriptional networking of metzincin metalloproteases in the cattle tick, Rhipicephalus (Boophilus) microplus. Vet Parasitol 2012, 186:403-414

118. Decrem Y, Mariller M, Lahaye K, Blasioli V, Beaufays J, Zouaoui Boudjeltia K, Vanhaeverbeek M, Cérutti M, Brossard M, Vanhamme L: The impact of gene knock-down and vaccination against salivary metalloproteases on blood feeding and egg laying by Ixodes ricinus. Int J Parasitol 2008, 38:549-560

119. Imamura S, da Silva Vaz I Jr, Konnai S, Yamada S, Nakajima C, Onuma M, Ohashi K: Effect of vaccination with a recombinant metalloprotease from Haemaphysalis longicornis. Exp Appl Acarol 2009, 48:345-358.

120. Francischetti IM, Mather TN, Ribeiro JM: Cloning of a salivary gland metalloprotease and characterization of gelatinase and fibrin(ogen)lytic activities in the saliva of the Lyme disease tick vector Ixodes scapularis. Biochem Biophys Res Commun 2003, 305:869-875.

121. Karanu FN, Rurangirwa FR, Mcguire TC, Jasmer DP: Haemonchus contortus: identification of proteases with diverse characteristics in adult worm excretory-secretory products. Exp Parasitol 1993, 77:362-371.

122. Borchert N, Becker-Pauly C, Wagner A, Fischer P, Stöcker W, Brattig NW: Identification and characterization of onchoastacin, an astacin-like metalloproteinase from the filaria Onchocerca volvulus. Microb Infect 2007, 9:498-506.

123. Lee J, Yen C: Protease secreted by the infective larvae of Angiostrongylus cantonensis and its role in the penetration of mouse intestine. Am J Trop Med Hyg 2005, 72:831-836.

124. Lai SC, Jiang ST, Chen KM, Lee HH: Matrix metalloproteinases activity demonstrated in the infective stage of the nematodes, Angiostrongylus cantonensis. Parasitol Res 2005, 97:466-471. 
125. Mulvenna J, Hamilton B, Nagaraj SH, Smyth D, Loukas A, Gorman JJ: Proteomics analysis of the excretory/secretory component of the blood-feeding stage of the hookworm, Ancylostoma caninum. Mol Cell Proteomics 2009, 8:109-121.

126. Mendez S, Zhan B, Goud G, Ghosh K, Dobardzic A, Wu W, Liu S, Deumic V, Dobardzic R, Liu Y: Effect of combining the larval antigens Ancylostoma secreted protein 2 (ASP-2) and metalloprotease 1 (MTP-1) in protecting hamsters against hookworm infection and disease caused by Ancylostoma ceylanicum. Vaccine 2005, 23:3123-3130.

127. Yoo WG, Kim D, Ju J, Cho PY, Kim TI, Cho S, Choi S, Park H, Kim T, Hong S: Developmental transcriptomic features of the carcinogenic liver fluke, Clonorchis sinensis. PLoS Negl Trop Dis 2011, 5:e1208.

128. Sajevic T, Leonardi A, Križaj I: Haemostatically active proteins in snake venoms. Toxicon 2011, 57:627-645

129. Kawanabe Y, Nauli S: Endothelin. Cell Mol Life Sci 2011, 68:195-203.

130. Wrighton $\mathrm{KH}$ : Protein degradation: Ensuring quality at the ribosome. Nature Rev Mol Cell Biol 2012, 14:1-1.

131. Muleng A, Sugino M, Nakajim M, Sugimoto C, Onuma M: Tick-encoded serine proteinase inhibitors (serpins); potential target antigens for tick vaccine development. J Vet Med Sci/Jpn Soc Vet Sci 2001, 63:1063-1069.

132. Armstrong PB: Proteases and protease inhibitors: a balance of activities in host-pathogen interaction. Immunobiology 2006, 211:263-281.

133. Cao J, Shi L, Zhou Y, Gao X, Zhang H, Gong H, Zhou J: Characterization of a new Kunitz-type serine protease inhibitor from the hard tick Rhipicephalus hemaphysaloides. Arch Insect Biochem Physiol 2013, 84:104-113.

134. Valdés JJ, Schwarz A, de Vaca IC, Calvo E, Pedra JH, Guallar V, Kotsyfakis M: Tryptogalinin is a tick Kunitz serine protease inhibitor with a unique intrinsic disorder. PLoS One 2013, 8:e62562.

135. Ibelli AM, Kim TK, Hill CC, Lewis LA, Bakshi M, Miller S, Porter L, Mulenga A: A blood meal-induced Ixodes scapularis tick saliva serpin inhibits trypsin and thrombin, and interferes with platelet aggregation and blood clotting. Int J Parasitol 2014, 2014:2014. in press, http://dx.doi.org/10.1016/j. ijpara.2014.01.010.

136. Chmelar J, Oliveira CJ, Rezacova P, Francischetti IMB, Kovarova Z, Pejler G, Kopacek P, Ribeiro JMC, Mares M, Kopecky J, Kotsyfakis M: A tick salivary protein targets cathepsin $\mathrm{G}$ and chymase and inhibits host inflammation and platelet aggregation. Blood 2011, 117:736-744.

137. Que X, Reed SL: Cysteine proteinases and the pathogenesis of amebiasis. Clin Microbiol Rev 2000, 13:196-206.

138. Parizi LF, Githaka NW, Acevedo C, Benavides U, Seixas A, Logullo C, Konnai S, Ohashi K, Masuda A: Sequence characterization and immunogenicity of cystatins from the cattle tick Rhipicephalus (Boophilus) microplus. Ticks Tick-Borne Dis 2013, 4:492-499.

139. Arolas JL, Lorenzo J, Rovira A, Castella J, Aviles FX, Sommerhoff CP: A carboxypeptidase inhibitor from the tick Rhipicephalus bursa: isolation, cDNA cloning, recombinant expression, and characterization. J Biol Chem 2005, 280:3441-3448.

140. Burnstock G: Purinergic signalling. Br J Pharmacol 2006, 147(Suppl):S172-S181.

141. Junger WG: Immune cell regulation by autocrine purinergic signalling. Nature Rev Immunol 2011, 11:201-212.

142. Kopáček P, Ždychová J, Yoshiga T, Weise C, Rudenko N, Law JH: Molecular cloning, expression and isolation of ferritins from two tick speciesOrnithodoros moubata and Ixodes ricinus. Insect Biochem Mol Biol 2003, 33:103-113.

143. Xu G, Fang QQ, Keirans JE, Durden LA: Ferritin gene coding sequences are conserved among eight hard tick species (Ixodida: Ixodidae). Ann Entomol Soc Am 2004, 97:567-573.

144. Mulenga A, Simser J, Macaluso K, Azad A: Stress and transcriptional regulation of tick ferritin $\mathrm{HC}$. Insect Mol Biol 2004, 13:423-433.

145. Hajdusek O, Almazán C, Loosova G, Villar M, Canales M, Grubhoffer L, Kopacek $\mathrm{P}$, de la Fuente J: Characterization of ferritin 2 for the control of tick infestations. Vaccine 2010, 28:2993-2998.

146. Cordill WJ: Characterization of Heme Lipoprotein in Ixodid Tick Saliva and Hemolymph. Oklahoma State University: Master Thesis; 2007.

147. Donohue KV, Khalil SMS, Mitchell RD, Sonenshine DE, Michael Roe R: Molecular characterization of the major hemelipoglycoprotein in ixodid ticks. Insect Mol Biol 2008, 17:197-208.

148. Graca-Souza A, Maya-Monteiro C, Paiva-Silva G, Braz GR, Paes MC, Sorgine MH, Oliveira MF, Oliveira PL: Adaptations against heme toxicity in blood-feeding arthropods. Insect Biochem Mol Biol 2006, 36:322-335.
149. Hajdusek O, Sojka D, Kopacek P, Buresova V, Franta Z, Sauman I, Winzerling J, Grubhoffer L: Knockdown of proteins involved in iron metabolism limits tick reproduction and development. Proc Natl Acad Sci U S A 2009, 106:1033-1038.

150. Maya-Monteiro CM, Daffre S, Logullo C, Lara FA, Alves EW, Capurro ML, Zingali R, Almeida IC, Oliveira PL: HeLp, a heme lipoprotein from the hemolymph of the cattle tick, Boophilus microplus. J Biol Chem 2000, 275:36584-36589.

151. Weinberg ED: Iron availability and infection. Biochim Biophys Acta 2009 1790:600-605

152. Rouault TA: Pathogenic bacteria prefer heme. Science 2004, 305:1577-1578.

153. Posey JE, Gherardini FC: Lack of a role for iron in the Lyme disease pathogen. Science 2000, 288:1651-1653.

154. Konhauser $\mathrm{KO}$, Kappler A, Roden EE: Iron in microbial metabolisms. Elements 2011, 7:89-93.

155. Mayfield JA, Dehner CA, DuBois JL: Recent advances in bacterial heme protein biochemistry. Curr Opin Chem Biol 2011, 15:260-266.

156. Schaible UE, Kaufmann SH: Iron and microbial infection. Nature Rev Microbiol 2004, 2:946-953.

157. Mulenga A, Macaluso KR, Simser JA, Azad AF: Dynamics of Rickettsia-tick interactions: identification and characterization of differentially expressed mRNAs in uninfected and infected Dermacentor variabilis. Insect Mol Biol 2003, 12:185-193.

158. Astrup T: Blood clotting and related processes. Adv Enzymol Relat Areas Mol Biol 2009, 10:1

159. Parizi LF, Rech H, Ferreira CAS, Imamura S, Ohashi K, Onuma M, Masuda A, da Silva Vaz J, Itabajara, Masuda A: Comparative immunogenicity of Haemaphysalis longicornis and Rhipicephalus (Boophilus) microplus calreticulins. Vet Parasitol 2009, 164:282-290.

160. Sanders ML, Jaworski DC, Sanchez JL, DeFraites RF, Glass GE, Scott AL, Raha S, Ritchie BC, Needham GR, Schwartz BS: Antibody to a CDNA-derived calreticulin protein from Amblyomma americanum as a biomarker of tick exposure in humans. Am J Trop Med Hyg 1998, 59:279-285.

161. Ferreira V, Valck C, Sanchez G, Gingras A, Tzima S, Molina MC, Sim R, Schwaeble W, Ferreira A: The classical activation pathway of the human complement system is specifically inhibited by calreticulin from Trypanosoma cruzi. J Immunol 2004, 172:3042-3050.

162. Suchitra S, Joshi P: Characterization of Haemonchus contortus calreticulin suggests its role in feeding and immune evasion by the parasite. Biochim Biophys Acta 2005, 1722:293-303.

163. Vaithilingam A, Teixeira JE, Miller PJ, Heron BT, Huston CD: Entamoeba histolytica cell surface calreticulin binds human c1q and functions in amebic phagocytosis of host cells. Infect Immun 2012, 80:2008-2018.

164. Oladiran A, Belosevic M: Trypanosoma carassii calreticulin binds host complement component $\mathrm{C} 1 \mathrm{q}$ and inhibits classical complement pathway-mediated lysis. Dev Comp Immunol 2010, 34:396-405

165. Davie EW, Fujikawa K, Kisiel W: The coagulation cascade: initiation, maintenance, and regulation. Biochemistry (NY) 1991, 30:10363-10370.

166. Gold LI, Rahman M, Blechman KM, Greives MR, Churgin S, Michaels J, Callaghan MJ, Cardwell NL, Pollins AC, Michalak M, Siebert JW, Levine JP, Gurtner GC, Nanney LB, Galiano RD, Cadacio CL: Overview of the role for calreticulin in the enhancement of wound healing through multiple biological effects. J Investigative Dermatol Symp Proc 2006, 11:57-65.

167. Sonenshine DE, Roe RM: Biology of Ticks. New York: Oxford University Press; 2013.

168. Chin D, Means AR: Calmodulin: a prototypical calcium sensor. Trends Cell Biol 2000, 10:322-328.

169. Anisuzzaman, Islam MK, Alim MA, Tsuji N: Longistatin, an EF-hand Ca2 + -binding protein from vector tick: identification, purification, and characterization. Methods Mol Biol 2013, 963:127-146.

170. Rozenblum GT, Gimona M: Calponins: Adaptable modular regulators of the actin cytoskeleton. Int J Biochem Cell Biol 2008, 40:1990-1995.

171. El-Mezgueldi M: Calponin. Int J Biochem Cell Biol 1996, 28:1185-1189.

172. Abe M, Takahashi K, Hiwada K: Effect of calponin on actin-activated myosin ATPase activity. J Biochem 1990, 108:835-838.

173. Gao Y, Gillen CM, Wheatly MG: Molecular characterization of the sarcoplasmic calcium-binding protein (SCP) from crayfish Procambarus clarkii. Comp Biochem Physiol Part B Biochem Mol Biol 2006, 144:478-487.

174. Shiomi K, Sato Y, Hamamoto S, Mita H, Shimakura K: Sarcoplasmic calcium-binding protein: identification as a new allergen of the black tiger shrimp Penaeus monodon. Int Arch Allergy Immunol 2008, 146:91-98. 
175. Ayuso R, Grishina G, Ibáñez MD, Blanco C, Carrillo T, Bencharitiwong R, Sánchez S, Nowak-Wegrzyn A, Sampson HA: Sarcoplasmic calcium-binding protein is an EF-hand-type protein identified as a new shrimp allergen. J Allergy Clin Immunol 2009, 124:114-120.

176. Bowman AS, Dillwith JW, Sauer JR: Tick salivary prostaglandins: Presence, origin and significance. Parasitol Today 1996, 12:388-396.

177. Dickinson R, O'Hagan J, Schotz M, Binnington K, Hegarty M: Prostaglandin in the saliva of the cattle tick Boophilus microplus. Aust J Exp Biol Med Sci 1976, 54:475-486.

178. Ribeiro JC, Evans PM, MacSwain J, Sauer J: Amblyomma americanum: Characterization of salivary prostaglandins E2 and F2a by RP-HPLC/ bioassay and gas chromatography-mass spectrometry. Exp Parasitol 1992, 74:112-116.

179. Bowman AS, Sauer JR, Zhu K, Dillwith JW: Biosynthesis of salivary prostaglandins in the lone star tick, Amblyomma americanum. Insect Biochem Mol Biol 1995, 25:735-741.

180. Poole NM, Mamidanna G, Smith RA, Coons LB, Cole JA: Prostaglandin E2 in tick saliva regulates macrophage cell migration and cytokine profile. Parasit Vectors 2013, 6:261.

181. Sá-Nunes A, Bafica A, Lucas DA, Conrads TP, Veenstra TD, Andersen JF, Mather TN, Ribeiro JMC, Francischetti IMB: Prostaglandin E2 is a major inhibitor of dendritic cell maturation and function in Ixodes scapularis saliva. J Immunol 2007, 179:1497-1505.

182. Gordon S: The role of the macrophage in immune regulation. Res Immunol 1998, 149:685-688.

183. Banchereau J, Briere F, Caux C, Davoust J, Lebecque S, Liu Y, Pulendran B, Palucka K: Immunobiology of dendritic cells. Annu Rev Immunol 2000, 18:767-811

184. White MV, Kaliner MA: Neutrophils and mast cells. I. Human neutrophilderived histamine-releasing activity. J Immunol 1987, 139:1624-1630.

185. Kemp DH, Bourne A: Boophilus microplus: the effect of histamine on the attachment of cattle-tick larvae-studies in vivo and in vitro. Parasitology 1980, 80:487-496.

186. Paine $\mathrm{SH}, \mathrm{Kemp} \mathrm{DH}$, Allen JR: In vitro feeding of Dermacentor andersoni (Stiles): effects of histamine and other mediators. Parasitology 1983, 86:419-428.

187. Brenner C, Bieganowski P, Pace HC, Huebner K: The histidine triad superfamily of nucleotide-binding proteins. J Cell Physiol 1999, 181:179-187.

188. Wang H, Nuttall PA: Excretion of host immunoglobulin in tick saliva and detection of IgG-binding proteins in tick haemolymph and salivary glands. Parasitology 1994, 109:525-530.

189. Wang $H$, Nuttall P: Immunoglobulin-G binding proteins in the ixodid ticks, Rhipicephalus appendiculatus, Amblyomma variegatum and Ixodes hexagonus. Parasitology 1995, 111:161-165.

190. Mulenga A, Khumthong R: Silencing of three Amblyomma americanum (L.) insulin-like growth factor binding protein-related proteins prevents ticks from feeding to repletion. J Exp Biol 2010, 213:1153-1161.

191. Frauenschuh A, Power CA, Déruaz M, Ferreira BR, Silva JS, Teixeira MM Dias JM, Martin T, Wells TNC, Proudfoot AEl: Molecular cloning and characterization of a highly selective chemokine-binding protein from the tick Rhipicephalus sanguineus. J Biol Chem 2007, 282:27250-27258.

192. Laing KJ, Secombes CJ: Chemokines. Dev Comp Immunol 2004, 28:443-460.

193. Borel JF, Feurer C, Gubler HU: StÃahelin H: Biological effects of cyclosporin A: A new antilymphocytic agent. Agents Actions 1994, 43:179-186.

194. Fischer G, Wittmann-Liebold B, Lang K, Kiefhaber T, Schmid FX: Cyclophilin and peptidyl-prolyl cis-trans isomerase are probably identical proteins. Nature 1989, 337:476-478

195. Wang P, Heitman J: The cyclophilins. Genome Biol 2005, 6:226.

196. Clipstone NA, Crabtree GR: Identification of calcineurin as a key signalling enzyme in T-lymphocyte activation. Nature 1992, 357:695-697.

197. Liu J, Albers MW, Wandless TJ, Luan S, Alberg DG, Belshaw PJ, Cohen P, Mackintosh C, Klee CB, Schreiber SL: Inhibition of T cell signaling by immunophilin-ligand complexes correlates with loss of calcineurin phosphatase activity. Biochemistry 1992, 31:3896-3901.

198. Elvers M, Herrmann A, Seizer $P$, Münzer $P$, Beck $S$, Schönberger T, Borst O, Martin-Romero FJ, Lang F, May AE, Gawaz M: Intracellular cyclophilin A is an important $\mathrm{Ca} 2+$ regulator in platelets and critically involved in arterial thrombus formation. Blood 2012, 120:1317-1326.

199. Maeda H, Boldbaatar D, Kusakisako K, Galay RL, Aung KM, Umemiya-Shirafuji R, Mochizuki M, Fujisaki K, Tanaka T: Inhibitory effect of cyclophilin A from the hard tick Haemaphysalis longicornis on the growth of Babesia bovis and Babesia bigemina. Parasitol Res 2013, 112:2207-2213.

200. Oliveira CJ, Anatriello E, de Miranda-Santos IK, Francischetti IM, Sá-Nunes A Ferreira BR, Ribeiro JMC: Proteome of Rhipicephalus sanguineus tick saliva induced by the secretagogues pilocarpine and dopamine. Ticks Tick-Borne Dis 2013, 4:469-477.

201. Aljamali M, Hern L, Kupfer D, Downard S, So S, Roe B, Sauer J, Essenberg R: Transcriptome analysis of the salivary glands of the female tick Amblyomma americanum (Acari: Ixodidae). Insect Mol Biol 2009, 18:129-154.

202. Ribeiro J, Alarcon-Chaidez F, Francischetti I, Mans BJ, Mather TN, Valenzuela JG, Wikel SK: An annotated catalog of salivary gland transcripts from Ixodes scapularis ticks. Insect Biochem Mol Biol 2006, 36:111-129.

203. Alarcon-Chaidez FJ, Sun J, Wikel SK: Transcriptome analysis of the salivary glands of Dermacentor andersoni Stiles (Acari: Ixodidae). Insect Biochem Mol Biol 2007, 37:48-71.

204. Thomas JA, Poland B, Honzatko R: Protein sulfhydryls and their role in the antioxidant function of protein S-thiolation. Arch Biochem Biophys 1995, 319:1-9

205. Leaver M, George S: A piscine glutathione S-transferase which efficiently conjugates the end-products of lipid peroxidation. Mar Environ Res 1998, 46:71-74.

206. Holmgren A: Antioxidant function of thioredoxin and glutaredoxin systems. Antioxidants Redox Signal 2000, 2:811-820.

207. Whitfield J: Gamma glutamyl transferase. Crit Rev Clin Lab Sci 2001, 38:263-355.

208. Mittler R: Oxidative stress, antioxidants and stress tolerance. Trends Plant Sci 2002, 7:405-410.

209. Rojkind M, Domínguez-Rosales J, Nieto N, Greenwel P: Role of hydrogen peroxide and oxidative stress in healing responses. Cell Mol Life Sci CMLS 2002, 59:1872-1891.

210. Vider J, Lehtmaa J, Kullisaar T, Vihalemm T, Zilmer K, Kairane Č, Landõr A Karu T, Zilmer M: Acute immune response in respect to exercise-induced oxidative stress. Pathophysiology 2001, 7:263-270.

211. Dreher-Lesnick S, Mulenga A, Simser JA, Azad AF: Differential expression of two glutathione S-transferases identified from the American dog tick Dermacentor variabilis. Insect Mol Biol 2006, 15:445-453.

212. Freitas D, Rosa R, Moraes J, Campos E, Logullo C: Relationship between glutathione S-transferase, catalase, oxygen consumption, lipid peroxidation and oxidative stress in eggs and larvae of Boophilus microplus (Acarina: Ixodidae). Comp Biochem Physiol Part A: Mol Integrative Physiol 2007, 146:688-694.

213. Callahan $H$, Crouch $R$, James E: Helminth anti-oxidant enzymes: a protective mechanism against host oxidants? Parasitol Today 1988, 4:218-225.

214. Trivedi V, Chand P, Srivastava K, Puri SK, Maulik PR, Bandyopadhyay U: Clotrimazole inhibits hemoperoxidase of Plasmodium falciparum and induces oxidative stress. Proposed antimalarial mechanism of clotrimazole. J Biol Chem 2005, 280:41129-41136.

215. Krieger S, Schwarz W, Ariyanayagam M, Fairlamb A: Krauth-Siegel R, Clayton C: Trypanosomes lacking trypanothione reductase are avirulent and show increased sensitivity to oxidative stress. Mol Microbiol 2000, 35:542-552.

216. Henkle-Dührsen K, Kampkötter A: Antioxidant enzyme families in parasitic nematodes. Mol Biochem Parasitol 2001, 114:129-142.

217. Müller S: Redox and antioxidant systems of the malaria parasite Plasmodium falciparum. Mol Microbiol 2004, 53:1291-1305.

218. Chiumiento L, Bruschi F: Enzymatic antioxidant systems in helminth parasites. Parasitol Res 2009, 105:593-603.

219. Parizi LF, Utiumi KU, Imamura S, Onuma M, Ohashi K, Masuda A: Cross immunity with Haemaphysalis longicornis glutathione S-transferase reduces an experimental Rhipicephalus (Boophilus) microplus infestation. Exp Parasitol 2011, 127:113-118.

220. Reeves MA, Bellinger FP, Berry MJ: The neuroprotective functions of selenoprotein $\mathrm{M}$ and its role in cytosolic calcium regulation. Antioxid Redox Signal 2010, 12:809-818.

221. Verma S, Hoffmann FW, Kumar M, Huang Z, Roe K, Nguyen-Wu E, Hashimoto AS, Hoffmann PR: Selenoprotein K knockout mice exhibit deficient calcium flux in immune cells and impaired immune responses. $\mathrm{J}$ Immunol 2011, 186:2127-2137.

222. Merk M, Zierow S, Leng L, Das R, Du X, Schulte W, Fan J, Lue $H$, Chen $Y$, Xiong $H$, Chagnon F, Bernhagen J, Lolis E, Mor G, Lesur O, Bucala R: 
The D-dopachrome tautomerase (DDT) gene product is a cytokine and functional homolog of macrophage migration inhibitory factor (MIF). Proc Natl Acad Sci U S A 2011, 108:E577-E585.

223. Poddar D, Basu A: Baldwin WM,3rd, Kondratov RV, Barik S, Mazumder B An extraribosomal function of ribosomal protein L13a in macrophages resolves inflammation. J Immunol 2013, 190:3600-3612.

224. LV J, Huang XR, Klug J, Frohlich S, Lacher P, Xu A, Meinhardt A, Lan HY: Ribosomal protein $\mathrm{S} 19$ is a novel therapeutic agent in inflammatory kidney disease. Clin Sci 2013, 124:627-637.

225. Velez AM, Howard M, Googe P: Ribosomal protein s6-ps240 is expressed in lesional skin from patients with autoimmune skin blistering diseases. North Am J Med Sci 2013, 5:604-608.

226. Cordeiro-Da-Silva A, Borges MC, Guilvard E, Ouaissi A: Dual role of the Leishmania major ribosomal protein S3a homologue in regulation of T- and B-cell activation. Infect Immun 2001, 69:6588-6596.

227. Spence JM, Clark VL: Role of ribosomal protein L12 in gonococcal invasion of Hec1B cells. Infect Immun 2000, 68:5002-5010.

228. Pockley AG: Heat shock proteins as regulators of the immune response. The Lancet 2003, 362:469-476.

229. Dai J, Narasimhan S, Zhang L, Liu L, Wang P, Fikrig E: Tick histamine release factor is critical for Ixodes scapularis engorgement and transmission of the lyme disease agent. PLOS Pathog 2010, 6:e1001205.

230. Krishna SS, Majumdar I, Grishin NV: Structural classification of zinc fingers: survey and summary. Nucleic Acids Res 2003, 31:532-550.

231. Han X, Fiehler R, Broze GJ Jr: Isolation of a protein Z-dependent plasma protease inhibitor. Proc Natl Acad Sci U S A 1998, 95:9250-9255.

232. Zhang J, Tu Y, Lu L, Lasky N, Broze GJ: Protein Z-dependent protease inhibitor deficiency produces a more severe murine phenotype than protein Z deficiency. Blood 2008, 111:4973-4978.

233. Ganz T: Defensins: antimicrobial peptides of innate immunity. Nat Rev Immunol 2003, 3:710-720.

234. Saito Y, Konnai S, Yamada S, Imamura S, Nishikado H, Ito T, Onuma M, Ohashi K: Identification and characterization of antimicrobial peptide, defensin, in the taiga tick, Ixodes persulcatus. Insect Mol Biol 2009, 18:531-539.

235. Todd SM, Sonenshine DE, Hynes WL: Tissue and life-stage distribution of a defensin gene in the Lone Star tick, Amblyomma americanum. Med Vet Entomol 2007, 21:141-147.

236. Ferreira CAS, Barbosa M, Silveira TCL, Valenzuela J, Da Silva Vaz I Jr, Masuda A: cDNA cloning, expression and characterization of a Boophilus microplus paramyosin. Parasitology 2002, 125:265-274.

237. Leal BF, Seixas A, Mattos RT, Coutinho ML, Masuda A, da Silva Vaz I Jr, Ferreira CA: Tissue expression and the host's immunological recognition of a Rhipicephalus microplus paramyosin. Vet Parasitol 2013, 197:304-311.

238. Sauer J, Essenberg R, Bowman A: Salivary glands in ixodid ticks: control and mechanism of secretion. J Insect Physiol 2000, 46:1069-1078.

239. Maritz-Olivier C, Louw A, Neitz A: Similar mechanisms regulate protein exocytosis from the salivary glands of ixodid and argasid ticks. J Insect Physiol 2005, 51:1390-1396.

240. Fawcett DW, Binnington K, Voigt WP: Cell biology of the ixodid tick salivary gland. Morphology, physiology, and behavioral biology of ticks/editors, John R. Sauer and J. Hair: Alexander; 1986.

241. Nene V, Lee D, Quackenbush J, Skilton R, Mwaura S, Gardner MJ, Bishop R $A v G l$, an index of genes transcribed in the salivary glands of the ixodid tick Amblyomma variegatum. Int J Parasitol 2002, 32:1447-1456.

242. Nene V, Lee D, Kang'a S, Skilton R, Shah T, de Villiers E, Mwaura S, Taylor D, Quackenbush J, Bishop R: Genes transcribed in the salivary glands of female Rhipicephalus appendiculatus ticks infected with Theileria parva. Insect Biochem Mol Biol 2004, 34:1117-1128.

243. Nakajima C, da Silva VI, Jr IS, Konnai S, Ohashi K, Onuma M: Random sequencing of cDNA library derived from partially-fed adult female Haemaphysalis longicornis salivary gland. J Vet Med Sci 2005, 67:1127-1131
244. Schwarz A, von Reumont BM, Erhart J, Chagas AC, Ribeiro JM, Kotsyfakis M: De novo Ixodes ricinus salivary gland transcriptome analysis using two next-generation sequencing methodologies. FASEB J 2013, 27:4745-4756.

245. Jaworski DC, Simmen FA, Lamoreaux W, Coons LB, Muller MT, Needham GR: A secreted calreticulin protein in ixodid tick (Amblyomma americanum) saliva. J Insect Physiol 1995, 41:369-375.

doi:10.1186/1471-2164-15-518

Cite this article as: Radulović et al: A 24-48 h fed Amblyomma americanum tick saliva immuno-proteome. BMC Genomics 2014 15:518.

\section{Submit your next manuscript to BioMed Central and take full advantage of:}

- Convenient online submission

- Thorough peer review

- No space constraints or color figure charges

- Immediate publication on acceptance

- Inclusion in PubMed, CAS, Scopus and Google Scholar

- Research which is freely available for redistribution

Submit your manuscript at www.biomedcentral.com/submit
C BioMed Central 